3

\title{
Phosphorus Retention in Lakes: A Critical Reassessment of Hypotheses and Static Models**
}

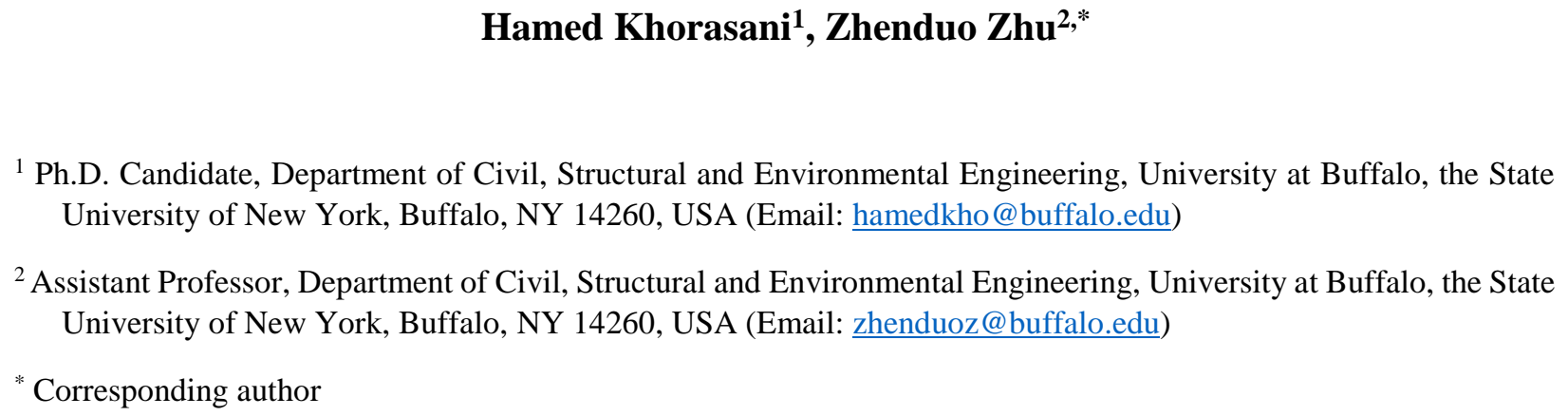

\section{Abstract}

Various hypotheses and models for phosphorus (P) retention in lakes are reviewed and 39 predictive models are assessed in three categories, namely mechanistic, semi-mechanistic, and strictly-empirical models. A large database consisting of 738 data points is gathered for the analyses. Assessing four pairs of competing hypotheses used in mechanistic models, we found that (i) simulating lakes as mixed-flow reactor is superior to plug-flow reactor hypothesis; (ii) modeling $\mathrm{P}$ loss as a second-order reaction outperforms the first-order reaction; (iii) $\mathrm{P}$ loss is better explained as a removal process throughout the lake volume than as a settling process across the sediments; and (iv) considering a fraction of $\mathrm{P}$ loading is associated with fast settling particles enhances lake total phosphorus (TP) predictions. Due to the systematic approach used for combining the hypotheses, some models are for the first time developed and assessed. For instance, the preeminent mechanistic model combines, for the first time, the second-order reaction hypothesis with the hypothesis that a specific proportion of $\mathrm{P}$ loading settles rapidly at the lake entrance. Results also showed that semi-mechanistic models outperform both mechanistic and strictlyempirical models since they take the form of a mechanistic model based on the physical 
representation of the lakes and utilize statistically acquired equations for unknown parameters. The

best-fit model is a semi-mechanistic model that adopts the mixed-flow reactor hypothesis with a second-order volumetric reaction rate that is calculated as a non-linear function of inflow TP concentration, lake average depth, and water retention time. This model predicts $77.8 \%$ of the variability of $\log 10$-transformed lake TP concentration, which is $4.2 \%$ higher than the best mechanistic model and $0.8 \%$ higher than the best strictly-empirical model. The findings of this study not only shed light on the understanding of $\mathrm{P}$ retention in lakes but also can be useful for assessment of data-limited lakes and large-scale hydrological models to simulate the P cycle.

Keywords: Phosphorus, Lake, Modeling, Retention, Eutrophication

\section{List of symbols}

$A=$ Surface area of the lake $\left(m^{2}\right)$

$L=$ Areal loading of TP $\left(m g\right.$ TP $\left.m^{-2} y r^{-1}\right)$

$Q_{\text {in }}, Q_{\text {out }}=$ Hydraulic inflow, outflow rate $\left(m^{3} y r^{-1}\right)$

$q_{s}=Q / A=$ Areal hydraulic loading rate $\left(m y r^{-1}\right)$

$R_{T P}=$ Lake TP retention

$T P_{\text {in }}, T P_{\text {out }}=$ Average inflow, outflow TP concentration $\left(m g T P m^{-3}\right.$ or $\left.\mu g T P L^{-1}\right)$

$\alpha=$ Fraction of $T P_{\text {in }}$ that does not settle fast in lake entrance

$T P_{\text {lake }}=$ Average lake TP concentration $\left(m g T P m^{-3}\right.$ or $\left.\mu g T P L^{-1}\right)$

$v=$ Settling velocity of TP containing materials $\left(m y r^{-1}\right)$

$v_{2}=$ Second-order settling coefficient of TP containing particles $\left(m^{4} m g T P^{-1} y r^{-1}\right)$

$V=$ Lake volume $\left(\mathrm{m}^{3}\right)$

$\bar{Z}=V / A=$ Average lake depth $(m)$

$\bar{w}=$ Average width of the lake $(m)$

$\tau_{w}=V / Q=$ Water residence time $(y r)$

$\rho=1 / \tau_{w}=$ Lake flushing rate $\left(y r^{-1}\right)$

$\sigma=$ First-order volumetric reaction rate constant $\left(y r^{-1}\right)$

$\sigma_{2}=$ Second-order volumetric reaction rate constant $\left(m^{3} m g T P^{-1} y r^{-1}\right)$

$m_{T P}=$ Mass of TP in lake water $(m g T P)$ 


\section{Introduction}

42 By providing relatively reliable storage of water for consumption during water deficit periods and 43 attenuation of floods, lakes and reservoirs play an important role in societies (Jørgensen et al., 44 2005). Due to generally lower water velocity, longer water residence time, and lower flushing rate, 45 lakes tend to trap the sediments they receive from tributaries. The accumulation of these sediments 46 from the watershed, as well as the deposition of detritus to the lake bottom, will eventually lead to

47 the filling of the lake, i.e. lake aging. As the lake ages, nutrients, especially nitrogen $(\mathrm{N})$ and 48 phosphorus (P) accumulate in the water column, and lake productivity increases which is referred 49 to as eutrophication (Vinçon-Leite and Casenave, 2019). However, human activities have 50 accelerated the eutrophication process by increasing the nutrients delivery to the aquatic systems 51 (Mekonnen and Hoekstra, 2018). Thus, anthropogenic eutrophication is one of the most important 52 elements of fresh and marine water quality deterioration (Hu et al., 2019; Smith and Schindler, 53 2009). One direct consequence of anthropogenic eutrophication comes in the form of massive algal 54 blooms (Granéli et al., 2008; Heisler et al., 2008), which are predicted to be intensified under 55 warmer water temperatures as climate changes (Gobler, 2020; Mukundan et al., 2020).

56 Eutrophication is a "wicked" problem, which is the consequence of various processes that operate 57 cumulatively. Considering the uniqueness of each lake and its surrounding area, there is no broadly 58 applicable set of best management practices that can be applied in watersheds to mitigate 59 phosphorus loading and its impact on all lakes (Thornton et al., 2013). Hence, eutrophication 60 management and lake restoration need integrated plans that are not only scientifically valid but 61 also socio-economically satisfying (Gibson et al., 2000). To that end, Khorasani et al., (2018) 62 developed a fourfold comprehensive framework that considers the upstream and downstream 63 interactions for the management of eutrophication in lakes and uses a social choice voting method 
64 to choose the best set of practicable actions. Lake eutrophication management includes a wide 65 range of approaches, from the reduction in external nutrient loading to sediment capping and control of internal loadings (Hickey and Gibbs, 2009; Zamparas and Zacharias, 2014) to biological

67 and hydrological manipulations and end-of-the-pipe methods (Cooke et al., 2016; Lürling et al., 2016). However, a successful management plan needs to be accompanied by a reduction in external nutrient loading to achieve sustainable results (Cooke et al., 2016). management practices. Various models for the simulation of ecological processes in lakes have

72 been developed during the last decades, from mechanistic (or process-based) models to empirical 73 models (Vinçon-Leite and Casenave, 2019), and from static models to dynamic models, to agent74 based models (Jørgensen and Bendoricchio, 2011). Although the static models are based on 75 simplifying assumptions, their low computational demand is an advantage in the large-scale 76 assessments of eutrophication and P retention (Maavara et al., 2015; Radomski and Carlson, 2018; 77 Wu et al., 2021; Xu et al., 2020), optimization of reservoir operation rules (Chen et al., 2019; Deng 78 et al., 2020; Xu et al., 2021; Zmijewski and Wörman, 2017), the evaluation of manipulative plans 79 for lakes with the risk of eutrophication (Estalaki et al., 2016; Kasprzak et al., 2018), and 80 paleolimnological studies (Moyle and Boyle, 2021). Though $\mathrm{N}$ and $\mathrm{P}$ are both vital for algae 81 growth in the aquatic environment (Lewis and Wurtsbaugh, 2008; Liang et al., 2021), it is widely 82 believed that the control of $\mathrm{P}$ seems the most promising approach for reduction of algal blooms in 83 freshwater systems (Kazmierczak et al., 2021; Le Moal et al., 2019; Schindler, 2012; Smith and 84 Schindler, 2009; Tong et al., 2017). Hence, predicting the P concentration in lakes is of crucial 85 importance, and static models can provide valuable estimates for the lake management goals. 
Phosphorus is subject to various biochemical transformations in lakes. Simple static models (as

87 explained in section 2) generally incorporate these transformations into a loss term in different ways with the assumption that a certain fraction of the external $\mathrm{P}$ loading retains in a lake (i.e. lake

89 P retention). The objective of this paper is to review and assess the static models, particularly four 90 pairs of competing hypotheses that are suggested for the lake $\mathrm{P}$ retention problem using a large 91 dataset of northern temperate lakes $(n=738)$. Although researchers have done extensive work to 92 evaluate some of the hypotheses (e.g. Walker 1985; Brett and Benjamin 2008), to our knowledge 93 this research is the first known comprehensive and systematic assessment of all four competing 94 hypotheses (see Table 1).

\section{Static Lake Phosphorus Models}

97 A general TP mass balance model for the lakes, assuming that in the long-term the lake is estimated 98 as a Continuously Stirring Tank Reactor (CSTR), is as follows:

$$
\frac{\Delta m_{T P}}{\Delta t}=\text { Input }- \text { Output }- \text { LosS }
$$

99 Based on some previous models in the early 1960s and using the data of 8 Swiss lakes, 100 Vollenweider (1969) hypothesized that the loss of the TP from the lake water column to the 101 sediments is a linear function of the TP mass in water as follows:

$$
\frac{\Delta m_{S}}{\Delta t}=\sigma m_{T P}
$$

102 Using Vollenweider's assumptions, that (i) the concentration of TP in output $\left(T P_{\text {out }}\right)$ is equal to 103 the lake-averaged TP concentration $\left(T P_{l a k e}\right)$, (ii) the water input and output of the lake are equal 104 (i.e., $\left.Q_{\text {in }}=Q_{\text {out }}=Q\right)$ and lake volume is constant $(\Delta V=0)$, (iii) the lake is in steady-state 
$105\left(\Delta T P_{\text {lake }} / \Delta t=0\right)$, and (iv) there is no net internal loading of $\mathrm{TP}$, the mass balance equation (Eq. 106 1) can be rewritten as follows:

$$
V \frac{\Delta T P_{\text {lake }}}{\Delta t}=Q \cdot T P_{\text {in }}-Q \cdot T P_{\text {lake }}-\sigma \cdot V \cdot T P_{\text {lake }}=0
$$

107 By assuming that the mean water residence time $\left(\tau_{w}\right)$ in lakes is calculated as $\tau_{w}=V / Q$, 108 rearranging Eq. (3) takes the following form:

$$
T P_{\text {lake }}=\frac{T P_{\text {in }}}{1+\sigma \tau_{w}}
$$

109 where all the parameters except $\sigma$ can be directly measured for a lake. Eq. (3) assumes that there 110 are two outputs for the TP after entering the lake, i.e. it either is washed out of the lake or is retained 111 in the water column or is removed from lake volume via several reactions that are lumped and 112 simplified as a first-order reaction. However, other researchers (e.g., Chapra, 1975; Imboden, 113 1974; Lorenzen, 1973) treated the TP removal through the lake mainly as the sedimentation 114 process of P-containing particles with the settling velocity $(v)$ to the sediment surface (which is 115 assumed to be equal to lake surface area). In this approach Eqs. (2) and (4) take the following 116 form:

$$
\begin{aligned}
& \frac{\Delta m_{S}}{\Delta t}=v \cdot A \cdot T P_{\text {lake }} \\
& T P_{\text {lake }}=\frac{T P_{\text {in }}}{1+\frac{v}{\bar{Z}} \tau_{w}}
\end{aligned}
$$

117 With a slightly larger database $(n=31)$, Vollenweider (1975) also suggested that the loss rate 118 constant $(\sigma)$ "depends on mean depth to a high degree" and obtained an approximation of $\sigma=$ $119\left(10 m y r^{-1}\right) / \bar{z}$. 
120 In an attempt to find an alternative for the Vollenweider's model with parameters that are all 121 directly measurable, Dillon and Rigler (1974) used the areal loading of TP ( $L$, see Eq. 7) to 122 introduce the lake TP retention $\left(R_{T P}\right)$ which is defined in Eq. (8).

$$
\begin{aligned}
& L=\frac{Q \cdot T P}{A} \\
& R_{T P}=1-\frac{L_{\text {out }}}{L_{\text {in }}}=1-\frac{\left(Q_{\text {in }} \cdot T P_{\text {in }}\right) / A}{\left(Q_{\text {out }} \cdot T P_{\text {out }}\right) / A}=1-\frac{T P_{\text {out }}}{T P_{\text {in }}}
\end{aligned}
$$

123 The input areal loading of TP is the sum of all the external loads of TP that enter the lake from 124 different sources and the output load is the output of TP loads through the lake outlet. Using this 125 approach, the loss term and the Vollenweider equation takes the following forms:

$$
\begin{aligned}
& \frac{\Delta m_{S}}{\Delta t}=R_{T P} \cdot Q \cdot T P_{\text {in }} \\
& T P_{\text {lake }}=T P_{\text {in }}\left(1-R_{T P}\right)
\end{aligned}
$$

126 Replacing the $R_{T P}$ from Eq. (8) into Eq. (10) results in the basic assumption of the well-mixed 127 lake where the TP concentration in the outlet is equal to the average lake $\mathrm{TP}$ concentration 128 suggested by Vollenweider:

$$
T P_{\text {lake }}=T P_{\text {in }}\left(1-R_{T P}\right)=T P_{\text {in }}\left[1-\left(1-\frac{T P_{\text {out }}}{T P_{\text {in }}}\right)\right]=T P_{\text {out }}
$$

129 However, this is undeniable that further attempts to develop equations for the prediction of $R_{T P}$ 130 have resulted in a better understanding of the TP retention problem in lakes. One of the general 131 forms of $R_{T P}$ prediction equations is $R_{P}=a /(a+b)$. It can be shown that if $b$ is equal to lake 132 flushing rate $(\rho)$ then $a$ is essentially the loss rate constant $(\sigma)$, while if $b$ is equal to areal hydraulic 133 loading $\left(q_{s}\right)$, then $a$ is essentially the settling velocity $(v)$ (Chapra, 1975; Dillon \& Kirchner, 1975; 
134 Kirchner \& Dillon, 1975). There are also other forms of empirical equations for $R_{T P}$ in the 135 literature as shown in next sections.

136 Prior research has interestingly enough suggested that empirical models of lake TP retention may 137 subsequently be explained with a mechanism. For instance, Jones and Bachman (1976) observed 138 that the Vollenweider model would perform better when $T P_{\text {in }}$ is multiplied by a constant 139 coefficient $(\alpha)$ (See Eq. 12). They estimated $\alpha=0.84$ using a database of 51 lakes, and they also 140 observed that after removal of urban lakes from the database, $\alpha$ increases to 0.97 and the model 141 performs slightly better. Hence, they speculated that $\alpha$ is associated with the different 142 sedimentation properties of TP loadings. Canfield and Bachman (1981) hypothesized that after 143 sedimentation of fast settling particulate $\mathrm{P},(1-\alpha) T P_{\text {in }}$, near the inlet of lakes, $\alpha$ is a constant 144 fraction of $T P_{i n}$ that reaches the open waters and has slower removal rate. Chapra (1982) also used 145 two pools for rapidly settling and slowly settling fractions of $\mathrm{P}$, and showed that if $146 v_{\text {rapidly-settling }} \gg v_{\text {slowly-settling }}$ then the constant coefficient in the numerator $(\alpha)$ represents 147 the $\mathrm{P}$ fraction that has slower removal in the main basin of lake.

$$
T P_{\text {lake }}=\frac{\alpha T P_{\text {in }}}{1+\sigma \tau_{w}} \text { or } \frac{\alpha T P_{\text {in }}}{1+\frac{v}{\bar{Z}} \tau_{w}}
$$

148 Higgins and Kim (1981) proposed the hypothesis to simulate the lakes as a Plug Flow Reactor 149 (PFR) as an alternative to the CSTR approach, to consider the longitudinal TP concentration 150 gradient. Assuming that the lake is a rectangular channel with uniform width and depth, the mass 151 balance equation in Eq. (3) in steady-state is as follows:

$$
\bar{w} \bar{Z} \Delta x \frac{d T P_{x}}{d t}=C Q-(C+\Delta C) Q-\sigma T P_{x} \bar{w} \bar{Z} \Delta x=0
$$


152 where $\bar{w}$ and $\bar{z}$ are width and depth of the lake, respectively, $x$ is the distance from lake entrance

153 and $T P_{x}$ is the TP concentration in cross-section $x$. By simplifying and integrating Eq. (13), the

154 PFR lake model is as follows:

$$
T P_{x}=T P_{\text {in }} \exp \left(-\frac{\sigma \bar{w} \bar{z} x}{Q}\right)=T P_{\text {in }} \exp \left(-\sigma \tau_{w_{x}}\right)
$$

155 where $\tau_{w_{x}}$ is the mean water retention time from lake entrance to cross-section $x$. If $x$ is equal to 156 the length of the lake then $\tau_{w_{x}}=\tau_{w}$. By integration of Eq. (14), the mean $T P_{\text {lake }}$ is calculated as 157 follows:

$$
T P_{\text {lake }}=\frac{T P_{\text {in }}}{\sigma \tau_{w}}\left(1-\exp \left(-\sigma \tau_{w}\right)\right)
$$

158 However, Higgins and Kim (1981) did not compare the overall performance of the CSTR model 159 and the PFR model with any dataset. Walker (1985) compared the two types of models and 160 concluded that the CSTR models generally outperform their PFR counterparts, suggesting a 161 completely mixed hypothesis might be generally better than the plug flow hypothesis for lake TP 162 concentrations.

163 Another important hypothesis in the development of the Vollenweider model is that the loss term 164 is linearly correlated to TP mass in the water column, which implies that the TP loss is the first165 order reaction. This hypothesis was initially based on the data of four lakes in Vollenweider (1968). 166 Dillon (1974) theoretically investigated the use of a second-order reaction form. Walker (1985) 167 performed a more comprehensive study and investigated the case in which the loss term per unit 168 volume of the lake is a quadratic function of $T P_{\text {lake }}$ :

$$
\frac{1}{V} \frac{\Delta m_{S}}{\Delta t}=\sigma_{2} \cdot T P_{\text {lake }}^{2}
$$


169 The steady-state mass balance equation, in which terms are expressed per unit volume of the lake,

170 is as follows:

$$
\frac{1}{V} \frac{\Delta m_{T P}}{\Delta t}=\frac{Q \cdot T P_{\text {in }}}{V}-\frac{Q \cdot T P_{\text {lake }}}{V}-\sigma_{2} \cdot T P_{\text {lake }}^{2}=0
$$

171 By simplifying the aforementioned equation, the second-order version of the Vollenweider model 172 is as follows:

$$
T P_{\text {lake }}=\frac{-1+\sqrt{1+4 \sigma_{2} T P_{\text {in }} \tau_{w}}}{2 \sigma_{2} \tau_{w}}
$$

173 It is noteworthy to mention that in the second-order models, the dimension of loss/sedimentation 174 parameter $\left(\sigma_{2}\right)$ is no longer only the inverse of time (e.g., $y r^{-1}$ ), but the inverse of TP 175 concentration and time (e.g., $\left(m g m^{-3}\right)^{-1} y r^{-1}$ or equivalently, $\left.m^{3} m g^{-1} y r^{-1}\right)$. Also, it should 176 be mentioned that due to the dimension of $\sigma_{2}$, the terms of the mass balance equation need to be 177 expressed per volume of the lake. For the first-order reaction, even if the terms are expressed as 178 per volume of the lake, the derived equation will not differ. The derivation of the first-order model 179 using the per volume terms is presented in Supplementary Materials (Text S1).

180 After a comprehensive review of the literature (see Table 1), we found that there are mainly four 181 pairs of competing hypotheses: mixed vs. plug flow, volumetric reaction vs. areal sedimentation, 182 first-order vs. second-order reaction, and fraction $\alpha<1$ vs. $\alpha=1$. In addition to mechanistic 183 models, researchers have developed different semi-mechanistic and empirical models. Semi184 mechanistic models take their forms from mechanistic models, but their unknown parameter is a non-linear function of lake characteristics. Although Empirical models do not necessarily explain 186 the mechanisms with lake TP retention (See Table 4 for their list), we decided to include them in 187 this study and assess the performance of all different types of models. 
Table 1. Summary of the static lake TP retention models developed and the databases used in the studies as well as comparison with the current study.

\begin{tabular}{|c|c|c|c|c|c|c|c|c|c|c|c|}
\hline \multirow[b]{2}{*}{ Author (Year) } & \multicolumn{3}{|c|}{ Models Type } & \multicolumn{7}{|c|}{ Hypothesis } & \multirow[b]{2}{*}{ Database size $^{1}$} \\
\hline & 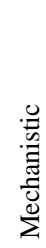 & 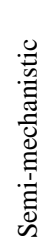 & 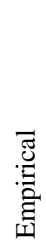 & 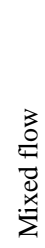 & $\begin{array}{l}\frac{3}{0} \\
\frac{a}{2} \\
\frac{00}{2} \\
\end{array}$ & 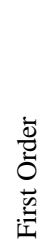 & $\begin{array}{l}\overline{0} \\
\overline{0} \\
0 \\
\overline{0} \\
\tilde{D} \\
\tilde{D}\end{array}$ & 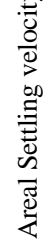 & 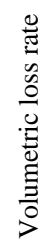 & 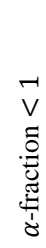 & \\
\hline Vollenweider (1969) & $\sqrt{ }$ & & & $\checkmark$ & & $\sqrt{ }$ & & & $\checkmark$ & & 8 Lakes \\
\hline Lorenzen (1973) & $\checkmark$ & & & $\checkmark$ & & $\checkmark$ & & $\checkmark$ & & & 4 Lakes \\
\hline Dillon (1974) & $\checkmark$ & & & $\checkmark$ & & $\checkmark$ & $\checkmark$ & & $\checkmark$ & & - \\
\hline Imboden (1974) & $\checkmark$ & & & $\checkmark$ & & $\checkmark$ & & $\checkmark$ & & & 13 Lakes \\
\hline Dillon and Rigler (1974) & $\checkmark$ & & & $\checkmark$ & & $\checkmark$ & & & & & 17 Lakes \\
\hline Dillon (1975) & $\checkmark$ & & & $\checkmark$ & & $\checkmark$ & & & $\checkmark$ & & 27 Lakes \\
\hline Vollenweider (1975) & $\checkmark$ & & & $\checkmark$ & & $\checkmark$ & & $\checkmark$ & $\checkmark$ & & 31 Lakes \\
\hline Kirchner and Dillon (1975) & & & $\checkmark$ & & & & & & & & 15 Lakes \\
\hline Chapra (1975) & $\checkmark$ & & $\checkmark$ & $\checkmark$ & & $\checkmark$ & & $\checkmark$ & & & 15 Lakes \\
\hline Dillon and Kirchner (1975) & $\checkmark$ & & & $\checkmark$ & & $\checkmark$ & & $\checkmark$ & & & 28 Lakes \\
\hline Snodgrass and O'Melia (1975) & $\checkmark$ & & & $\checkmark$ & & $\checkmark$ & & $\checkmark$ & & & 11 Lakes \\
\hline Larsen and Mercier (1976) & $\checkmark$ & $\checkmark$ & $\checkmark$ & $\checkmark$ & & $\checkmark$ & & $\checkmark$ & $\checkmark$ & & 20 Lakes \\
\hline Vollenweider (1976) & $\checkmark$ & $\checkmark$ & & $\checkmark$ & & $\checkmark$ & & $\checkmark$ & & & (194 Obs.) \\
\hline Jones and Bachman (1976) & $\checkmark$ & & & $\checkmark$ & & $\checkmark$ & & & $\checkmark$ & $\checkmark$ & 51 Lakes \\
\hline Chapra (1977) & $\checkmark$ & & & $\checkmark$ & & $\checkmark$ & & $\checkmark$ & & & 5 Great Lakes \\
\hline Ostrofsky (1978) & & & $\checkmark$ & & & & & & & & 53 Lakes \\
\hline Schindler et al. (1978) & & & $\checkmark$ & $\checkmark$ & & $\checkmark$ & & $\checkmark$ & & & 60 Lakes \\
\hline Yeasted and Morel (1978) & & & $\checkmark$ & & & & & & & & 128 Lakes \\
\hline Reckhow (1979) & & $\checkmark$ & & $\checkmark$ & & $\checkmark$ & & $\checkmark$ & & & 47 Lakes \\
\hline Chapra and Reckhow (1979) & & $\checkmark$ & & $\checkmark$ & & $\checkmark$ & & & $\checkmark$ & & 117 Lakes \\
\hline Reckhow and Chapra (1979) & & & $\checkmark$ & & & & & & & & 15 Lakes \\
\hline $\begin{array}{l}\text { Uttormark and Hutchins } \\
(1980)\end{array}$ & $\checkmark$ & $\checkmark$ & & $\checkmark$ & & $\checkmark$ & & $\checkmark$ & $\checkmark$ & & 23 lakes \\
\hline Canfield and Bachman (1981) & $\checkmark$ & $\checkmark$ & $\checkmark$ & $\checkmark$ & & $\checkmark$ & & $\checkmark$ & $\checkmark$ & $\checkmark$ & 704 Lakes (723 Obs.) \\
\hline Higgins and Kim (1981) & $\checkmark$ & & & $\checkmark$ & $\checkmark$ & $\checkmark$ & & $\checkmark$ & $\checkmark$ & & 18 Artificial Lakes \\
\hline Chapra (1982) & $\checkmark$ & & & $\checkmark$ & & $\checkmark$ & & $\checkmark$ & & $\checkmark$ & 13 Lakes \\
\hline Nurnberg (1984) & $\checkmark$ & $\checkmark$ & $\checkmark$ & $\checkmark$ & & $\checkmark$ & & $\checkmark$ & & & 90 Lakes \\
\hline Stauffer (1985) & & & $\checkmark$ & & & & & & & & 20 Lakes \\
\hline Walker (1985) & $\checkmark$ & $\checkmark$ & $\checkmark$ & $\checkmark$ & $\checkmark$ & $\checkmark$ & $\checkmark$ & $\checkmark$ & $\checkmark$ & & (696 Obs.) \\
\hline Reckhow (1988) & $\checkmark$ & $\checkmark$ & & $\checkmark$ & & $\checkmark$ & & & $\checkmark$ & & 70 Lakes \\
\hline Prairie (1989) & $\checkmark$ & $\checkmark$ & & $\checkmark$ & & $\checkmark$ & & $\checkmark$ & $\checkmark$ & $\checkmark$ & 112 Lakes \\
\hline Foy (1992) & $\checkmark$ & $\checkmark$ & $\checkmark$ & $\checkmark$ & & $\checkmark$ & & $\checkmark$ & & & 10 Lakes \\
\hline Dillon and Molot (1996) & $\checkmark$ & & & $\checkmark$ & & $\checkmark$ & & $\checkmark$ & & & 7 Lakes \\
\hline Hejzlar et al. (2006) & $\checkmark$ & $\checkmark$ & $\checkmark$ & $\checkmark$ & & $\checkmark$ & & $\checkmark$ & $\checkmark$ & & 212 Lakes \\
\hline Bryhn and Håkanson (2007) & $\checkmark$ & $\checkmark$ & $\checkmark$ & $\checkmark$ & & $\checkmark$ & & $\checkmark$ & $\checkmark$ & & 41 Lakes \\
\hline Brett and Benjamin (2008) & $\checkmark$ & $\checkmark$ & $\checkmark$ & $\checkmark$ & & $\checkmark$ & & $\checkmark$ & $\checkmark$ & $\checkmark$ & 305 Lakes \\
\hline Kõiv (2011) & & & $\checkmark$ & & & & & & & & 54 Lakes \\
\hline Abell et al. (2019) & & & $\checkmark$ & & & & & & & & 84 Lakes \\
\hline Current Study & $\checkmark$ & $\checkmark$ & $\sqrt{ }$ & $\checkmark$ & $\checkmark$ & $\checkmark$ & $\checkmark$ & $\checkmark$ & $\checkmark$ & $\checkmark$ & (738 Obs.) \\
\hline
\end{tabular}

${ }^{1}$ The numbers inside parentheses are the number of observational (Obs.) points. If the measurements in one lake are repeated in different years, the number of observations in the database surpasses the number of lakes. 


\section{Materials and Methods}

193 This section presents the materials, including the models and their classification criteria, and the 194 database of the lakes. The methods for fitting the models and their evaluation as well as the 195 Bayesian Information Criterion (BIC) used for the comparison of the models are presented in 196 Appendix 1.

\subsection{Model Development and Classification}

199 Lake phosphorus models generally can be divided into three categories, i.e., mechanistic, semi200 mechanistic, and strictly-empirical. Mechanistic models are explicitly based on theoretical 201 representations of lake mixing and TP dynamics and are derived from first principles. The 202 hypotheses reviewed in section 2 are combined to derive different mechanistic models as presented

203 in Table 2. The dimension of unknown parameters in mechanistic models lies in the integer 204 combination of base units that hold physical meanings. Each of the mechanistic models has one or 205 two unknown parameters. It is noteworthy to mention that, to our best knowledge, this is the first 206 time that the combination of the second-order reaction hypothesis and $\alpha$-fraction hypothesis is 207 considered and assessed. Moreover, this is the first time the average forms of the plug-flow models 208 and their combination with $\alpha$-fraction hypothesis are tested with a large dataset.

209 Empirical models, on the other hand, are obtained from statistical analysis and do not rely on the 210 conceptual representation of the lake. Semi-mechanistic models partly rely on the physical 211 representation of the lake and partly benefit from the statistical analysis (Braake et al., 1998). In 212 this paper, semi-mechanistic models adopt their basic structure from mechanistic models but the 213 unknown parameters, i.e., the $\mathrm{P}$ removal rates, are obtained by fitting an empirical equation to the 
214 data. Overall, 39 different models are assessed in this study including 16 mechanistic (see Table

219 Table 2. List of mechanistic models and their basic hypotheses

\begin{tabular}{|c|c|c|c|c|}
\hline $\begin{array}{l}\text { Overall } \\
\text { Model } \\
\text { No. }\end{array}$ & $\begin{array}{l}\text { Intra- } \\
\text { type } \\
\text { model } \\
\text { No. }\end{array}$ & Model & Formulation $\left(T P_{\text {lake }}=\right)$ & Description \\
\hline 1 & 1 & $\begin{array}{l}\text { Plug-Flow, First-Order, Constant Loss } \\
\text { Rate }\end{array}$ & $\frac{T P_{\text {in }}}{k_{1} \tau_{w}}\left[1-\exp \left(-k_{1} \tau_{w}\right)\right]$ & $k_{1}=\sigma$ is the volumetric loss rate $(1 / \mathrm{yr})$ \\
\hline 2 & 2 & $\begin{array}{l}\text { Plug-Flow, First-Order, Constant } \\
\text { Settling Velocity }\end{array}$ & $\frac{T P_{\text {in }}}{\frac{k_{1}}{Z} \tau_{w}}\left[1-\exp \left(-\frac{k_{1}}{Z} \tau_{w}\right)\right]$ & $k_{1}=v$ is the settling velocity $(\mathrm{m} / \mathrm{yr})$ \\
\hline 3 & 3 & $\begin{array}{l}\text { Plug-Flow, First-Order, Constant Loss } \\
\text { Rate for Constant Fraction of } \mathrm{TP}_{\text {in }}\end{array}$ & $\frac{a T P_{i n}}{k_{1} \tau_{w}}\left[1-\exp \left(-k_{1} \tau_{w}\right)\right]$ & $\begin{array}{l}k_{1}=\sigma \text { is the volumetric loss rate }(1 / \mathrm{yr}), a \text { is a } \\
\text { constant fraction of } \mathrm{TP}_{\text {in }}\end{array}$ \\
\hline 4 & 4 & $\begin{array}{l}\text { Plug-Flow, First-Order, Constant } \\
\text { Settling Velocity for Constant Fraction } \\
\text { of } \mathrm{TP}_{\text {in }}\end{array}$ & $\frac{a T P_{\text {in }}}{\frac{k_{1}}{Z} \tau_{w}}\left[1-\exp \left(-\frac{k_{1}}{Z} \tau_{w}\right)\right]$ & $\begin{array}{l}k_{1}=v \text { is the settling velocity }(\mathrm{m} / \mathrm{yr}), a \text { is a } \\
\text { constant fraction of } \mathrm{TP}_{\mathrm{in}}\end{array}$ \\
\hline 5 & 5 & $\begin{array}{l}\text { Plug-Flow, Second-Order, Constant } \\
\text { Loss Rate }\end{array}$ & $\frac{\ln \left(k_{1} T P_{i n} \tau_{w}+1\right)}{k_{1} \tau_{w}}$ & $\begin{array}{l}k_{1}=\sigma_{2} \text { is the effective second-order loss rate } \\
\left(\mathrm{m}^{3} /(\mathrm{mg} . \mathrm{yr})\right)\end{array}$ \\
\hline 6 & 6 & $\begin{array}{l}\text { Plug-Flow, Second-Order, Constant } \\
\text { Settling Coefficient }\end{array}$ & $\frac{\ln \left(\frac{k_{1}}{Z} T P_{i n} \tau_{w}+1\right)}{\frac{k_{1}}{Z} \tau_{w}}$ & $\begin{array}{l}k_{1}=v_{2} \text { is the effective second-order settling } \\
\text { coefficient }\left(\mathrm{m}^{4} /(\mathrm{mg} . \mathrm{yr})\right)\end{array}$ \\
\hline 7 & 7 & $\begin{array}{l}\text { Plug-Flow, Second-Order, Constant } \\
\text { Loss Rate for Constant Fraction of } \mathrm{TP}_{\mathrm{in}}\end{array}$ & $\frac{\ln \left(k_{1} a T P_{i n} \tau_{w}+1\right)}{k_{1} \tau_{w}}$ & $\begin{array}{l}k_{1}=\sigma_{2} \text { is the effective second-order loss rate } \\
\left(\mathrm{m}^{3} /(\mathrm{mg} \cdot \mathrm{yr})\right), a \text { is a constant fraction of } \mathrm{TP}_{\text {in }}\end{array}$ \\
\hline 8 & 8 & $\begin{array}{l}\text { Plug-Flow, Second-Order, Constant } \\
\text { Settling Coefficient for Constant } \\
\text { Fraction of } \mathrm{TP}_{\text {in }}\end{array}$ & $\frac{\ln \left(\frac{k_{1}}{Z} a T P_{i n} \tau_{w}+1\right)}{\frac{k_{1}}{Z} \tau_{w}}$ & $\begin{array}{l}k_{1}=v_{2} \text { is the effective second-order settling } \\
\text { coefficient }\left(\mathrm{m}^{4} /(\mathrm{mg} . \mathrm{yr})\right), a \text { is a constant } \\
\text { fraction of } \mathrm{TP}_{\text {in }}\end{array}$ \\
\hline 9 & 9 & Mixed, First-Order, Constant Loss Rate & $\frac{T P_{i n}}{1+k_{1} \tau_{w}}$ & $k_{1}=\sigma$ is the volumetric loss rate $(1 / \mathrm{yr})$ \\
\hline 10 & 10 & $\begin{array}{l}\text { Mixed, First-Order, Constant Settling } \\
\text { Velocity }\end{array}$ & $\frac{T P_{\text {in }}}{1+\frac{k_{1}}{Z} \tau_{w}}$ & $k_{1}=v$ is the settling velocity $(\mathrm{m} / \mathrm{yr})$ \\
\hline 11 & 11 & $\begin{array}{l}\text { Mixed, First-Order, Constant Loss Rate } \\
\text { for Constant Fraction of } \mathrm{TP}_{\mathrm{in}}\end{array}$ & $\frac{a T P_{\text {in }}}{1+k_{1} \tau_{w}}$ & $\begin{array}{l}k_{1}=\sigma \text { is the volumetric loss rate }(1 / \mathrm{yr}), a \text { is a } \\
\text { constant fraction of } \mathrm{TP}_{\text {in }}\end{array}$ \\
\hline 12 & 12 & $\begin{array}{l}\text { Mixed, First-Order, Constant Settling } \\
\text { Velocity for Constant Fraction of } \mathrm{TP}_{\text {in }}\end{array}$ & $\frac{a T P_{i n}}{1+\frac{k_{1}}{Z} \tau_{w}}$ & $\begin{array}{l}k_{1}=v \text { is the settling velocity }(\mathrm{m} / \mathrm{yr}), a \text { is a } \\
\text { constant fraction of } \mathrm{TP}_{\mathrm{in}}\end{array}$ \\
\hline 13 & 13 & $\begin{array}{l}\text { Mixed, Second-Order, Constant Loss } \\
\text { Rate }\end{array}$ & $\frac{-1+\left(1+4 k_{1} \tau_{w} T P_{i n}\right)^{0.5}}{2 k_{1} \tau_{w}}$ & $\begin{array}{l}k_{1}=\sigma_{2} \text { is the effective second-order loss rate } \\
\left(\mathrm{m}^{3} /(\mathrm{mg} \cdot \mathrm{yr})\right)\end{array}$ \\
\hline 14 & 14 & $\begin{array}{l}\text { Mixed, Second-Order, Constant } \\
\text { Settling Coefficient }\end{array}$ & $\frac{-1+\left(1+4 \frac{k_{1}}{Z} \tau_{w} T P_{\text {in }}\right)^{0.5}}{2 \frac{k_{1}}{Z} \tau_{w}}$ & $\begin{array}{l}k_{1}=v_{2} \text { is the effective second-order settling } \\
\text { coefficient }\left(\mathrm{m}^{4} /(\mathrm{mg} . \mathrm{yr})\right)\end{array}$ \\
\hline 15 & 15 & $\begin{array}{l}\text { Mixed, Second-Order, Constant Loss } \\
\text { Rate for Constant Fraction of } \mathrm{TP}_{\text {in }}\end{array}$ & $\frac{-1+\left(1+4 k_{1} \tau_{w} a T P_{i n}\right)^{0.5}}{2 k_{1} \tau_{w}}$ & $\begin{array}{l}k_{1}=\sigma_{2} \text { is the effective second-order loss rate } \\
\left(\mathrm{m}^{3} /(\mathrm{mg} \cdot \mathrm{yr})\right), a \text { is a constant fraction of } \mathrm{TP}_{\mathrm{in}}\end{array}$ \\
\hline 16 & 16 & $\begin{array}{l}\text { Mixed, Second-Order, Constant } \\
\text { Settling Coefficient for Constant } \\
\text { Fraction of } \mathrm{TP}_{\text {in }}\end{array}$ & $\frac{-1+\left(1+4 \frac{k_{1}}{Z} \tau_{w} a T P_{i n}\right)^{0.5}}{2 \frac{k_{1}}{Z} \tau_{w}}$ & $\begin{array}{l}k_{1}=v_{2} \text { is the effective second-order settling } \\
\text { coefficient }\left(\mathrm{m}^{4} /(\mathrm{mg} . \mathrm{yr})\right), a \text { is a constant } \\
\text { fraction of } \mathrm{TP}_{\text {in }}\end{array}$ \\
\hline
\end{tabular}


Table 3. List of semi-mechanistic models and their effective loss rate description

\begin{tabular}{|c|c|c|c|c|}
\hline $\begin{array}{l}\text { Overall } \\
\text { Model No.* }\end{array}$ & $\begin{array}{l}\text { Intra-type } \\
\text { Model No. }\end{array}$ & Model & Formulation $\left(T P_{\text {lake }}=\right)$ & Description \\
\hline 17 & 1 & Plug Flow, First-Order & $\frac{T P_{i n}}{k_{1} \tau_{w}^{k_{2}}}\left[1-\exp \left(-k_{1} \tau_{w}^{k_{2}}\right)\right]$ & The effective loss rate is $\sigma=k_{1} \tau_{w}^{k_{2}-1}$ \\
\hline 18 & 2 & Plug Flow, First-Order & $\begin{array}{l}\frac{T P_{i n}}{k_{1} \tau_{w}^{k_{2}} T P_{i n}^{k_{3}}}\left[1-\exp \left(-k_{1} \tau_{w}^{k_{2}} T P_{i n}^{k_{3}}\right)\right] \\
\quad T P_{i n}\end{array}$ & The effective loss rate $\sigma=k_{1} \tau_{w}^{k_{2}-1} T P_{i n}^{k_{3}}$ \\
\hline 19 & 3 & Plug Flow, First-Order & $\begin{array}{l}k_{1} \tau_{w}^{k_{2}} T P_{i n}^{k_{3}} z^{k_{4}} \\
\left.-\exp \left(-k_{1} \tau_{w}^{k_{2}} T P_{i n}^{k_{3}} z^{k_{4}}\right)\right]\end{array}$ & $\begin{array}{l}\text { The effective loss rate } \sigma= \\
k_{1} \tau_{w}^{k_{2}-1} T P_{i n}^{k_{3}} z^{k_{4}}\end{array}$ \\
\hline 20 & 4 & Plug Flow, Second-Order & $\frac{\ln \left(k_{1} \tau_{w}^{k_{2}} T P_{i n}+1\right)}{k_{1} \tau_{w}^{k_{2}}}$ & The effective loss rate is $\sigma_{2}=k_{1} \tau_{w}^{k_{2}-1}$ \\
\hline 21 & 5 & Plug Flow, Second-Order & $\frac{\ln \left(k_{1} \tau_{w}^{k_{2}} T P_{i n}^{k_{3}+1}+1\right)}{k_{1} \tau_{w}^{k_{2}} T P_{i n}^{k_{3}}}$ & The effective loss rate $\sigma_{2}=k_{1} \tau_{w}^{k_{2}-1} T P_{i n}^{k_{3}}$ \\
\hline 22 & 6 & Plug Flow, Second-Order & $\frac{\ln \left(k_{1} \tau_{w}^{k_{2}} z^{k_{3}} T P_{i n}^{k_{4}+1}+1\right)}{k_{1} \tau_{w}^{k_{2}} z^{k_{3}} T P_{i n}^{k_{4}}}$ & $\begin{array}{l}\text { The effective loss rate } \sigma_{2}= \\
k_{1} \tau_{w}^{k_{2}-1} T P_{i n}^{k_{3}} z^{k_{4}}\end{array}$ \\
\hline 23 & 7 & Mixed, First-Order & $\frac{T P_{\text {in }}}{1+k_{1} \tau_{w}^{k_{2}}}$ & The effective loss rate $\sigma=k_{1} \tau_{w}^{k_{2}-1}$ \\
\hline 24 & 8 & Mixed, First-Order & $\frac{T P_{i n}}{1+k_{1} \tau_{w}^{k_{2}} T P_{i n}^{k_{3}}}$ & The effective loss rate $\sigma=k_{1} \tau_{w}^{k_{2}-1} T P_{i n}^{k_{3}}$ \\
\hline 25 & 9 & Mixed, First-Order & $\frac{T P_{i n}}{1+k_{1} \tau_{w}^{k_{2}} T P_{i n}^{k_{3}} z^{k_{4}}}$ & $\begin{array}{l}\text { The effective loss rate } \sigma= \\
k_{1} \tau_{w}^{k_{2}-1} T P_{i n}^{k_{3}} z^{k_{4}}\end{array}$ \\
\hline 26 & 10 & Mixed, Second-Order & $\frac{-1+\left(1+4 k_{1} \tau_{w}^{k_{2}} T P_{i n}\right)^{0.5}}{2 k_{1} \tau_{w}^{k_{2}}}$ & The effective loss rate $\sigma_{2}=k_{1} \tau_{w}^{k_{2}-1}$ \\
\hline 27 & 11 & Mixed, Second-Order & $\frac{-1+\left(1+4 k_{1} \tau_{w}^{k_{2}} T P_{i n}^{k_{3}+1}\right)^{0.5}}{2 k_{1} \tau_{w}^{k_{2}} T P_{i n}^{k_{3}}}$ & The effective loss rate $\sigma_{2}=k_{1} \tau_{w}^{k_{2}-1} T P_{i n}^{k_{3}}$ \\
\hline 28 & 12 & Mixed, Second-Order & $\frac{-1+\left(1+4 k_{1} \tau_{w}^{k_{2}} T P_{i n}^{k_{3}+1} z^{k_{4}}\right)^{0.5}}{2 k_{1} \tau_{w}^{k_{2}} T P_{i n}^{k_{3}} z^{k_{4}}}$ & $\begin{array}{l}\text { The effective loss rate } \sigma_{2}= \\
k_{1} \tau_{w}^{k_{2}-1} T P_{i n}^{k_{3}} z^{k_{4}}\end{array}$ \\
\hline 29 & 13 & Mixed, Second-Order & $\frac{-1+\left(1+4 \sigma_{2} \tau_{w} T P_{i n}\right)^{0.5}}{2 \sigma \tau_{w}}$ & The effective loss rate $\sigma_{2}=\frac{k_{1} z}{k_{2} z+\tau_{w}} * *$ \\
\hline
\end{tabular}

* Overall model numbers continued from Table 2

** Obtained from Walker Jr. (1985) 
Table 4. List of strictly-empirical models and their references

\begin{tabular}{|c|c|c|c|c|}
\hline $\begin{array}{l}\text { Overall } \\
\text { Model } \\
\text { No.* }\end{array}$ & $\begin{array}{l}\text { Intra- } \\
\text { type } \\
\text { Model } \\
\text { No. }\end{array}$ & Model Name & Formulation $\left(T P_{\text {lake }}=\right)$ & Reference \\
\hline 30 & 1 & $\mathrm{~K} \& \mathrm{D}$ & $T P_{\text {in }}\left[1-\left(k_{1} \exp \left(-k_{2} \frac{Z}{\tau_{w}}\right)+\left(1-k_{1}\right) \exp \left(-k_{3} \frac{Z}{\tau_{w}}\right)\right)\right]$ & Kirchner and Dillon (1975) \\
\hline 31 & 2 & Ostrofsky1 & $T P_{\text {in }}\left[1-\left(k_{1} \exp \left(-k_{2} \frac{Z}{\tau_{w}}\right)+k_{3} \exp \left(-k_{4} \frac{Z}{\tau_{w}}\right)\right)\right]$ & \\
\hline 32 & 3 & Ostrofsky2 & $T P_{i n}\left[1-\frac{k_{1}}{k_{2}+\frac{Z}{\tau_{w}}}\right]$ & Ostrofsky(1978) \\
\hline 33 & 4 & L\&M1 & $T P_{\text {in }}\left[1-\left(k_{1}-k_{2} \ln \left(\frac{1}{\tau_{w}}\right)\right)\right]$ & Larsen and Marcier (1976) \\
\hline 34 & 5 & L\&M2 & $T P_{i n}\left[1-\left(k_{1}-k_{2} \ln \left(\frac{Z}{\tau_{w}}\right)\right)\right]$ & \\
\hline 35 & 6 & OECD & $k_{1}\left(\frac{T P_{i n}}{1+\sqrt{\tau_{w}}}\right)^{k_{2}}$ & Vollenweider (1976) \\
\hline 36 & 7 & Foy1 & $\begin{array}{l}k_{1} \frac{T P_{i n}}{\left(1+\sqrt{\tau_{w}}\right)^{k_{2}}} \\
\frac{\left(k_{1} T P_{i n}\right)^{k_{2}}}{\left(1+\sqrt{\tau_{w}}\right)^{k_{3}}}\end{array}$ & (Foy, 1992) \\
\hline 38 & 9 & $\mathrm{~B} \& \mathrm{~B}$ & $k_{1} T P_{i n}^{k_{2}} \tau_{w}^{k_{3}}$ & Brett and Benjamin (2008) \\
\hline 39 & 10 & Kõiv et al. & $T P_{i n}\left[k_{1}+k_{2} \log \left(T P_{i n}\right)+k_{3} \log \tau_{w}\right]$ & Kõiv et al. (2011) \\
\hline
\end{tabular}

\subsection{Database Development}

231 The database used in this paper is a compilation of three data sets and has 738 observation data 232 points. The largest database of the three is the National Eutrophication Survey (NES) dataset 233 conducted by the U.S. Environmental Protection Agency (EPA) from 1972 to 1975 across the 234 contiguous United States (USEPA, 1975). The NES database has 775 lakes and to our best 235 knowledge is the largest database that includes the phosphorus data of lake input, in-lake, and output. Stachelek et al. (2018) digitized the NES tables and we carefully examined the digital

237 database and corrected some faulty entries by comparing the reported and recalculated water 238 retention time, TP and TN retention values, and the extreme values for TP and TN concentrations 239 (data available at https://github.com/ReproducibleQM/NES). The second database is from Hejzlar et al. (2006) and includes 264 observations of which 6 observations for the West Point Lake in 
241 Georgia state are the results of simulation rather than direct measurements. After the removal of 242 West Point Lake, 258 observations of which two-thirds are located outside of the US (mostly 243 Europe and Canada) are added to our database. The third database is from Brett and Benjamin 244 (2008) which includes 305 lakes of which 178 lakes overlap with the other two datasets. Hence, 245 only 127 lakes from Brett and Benjamin (2008) are added to our database of which $22 \%$ are located 246 in Europe and the rest is equally distributed between the US and Canada.

247 In total, 1160 data points are obtained after combining the three databases of which 122 were 248 excluded due to the lack of data for water retention time. Then, 42 lakes were removed because of 249 inaccurate water retention time (5\% outliers in the ratio between calculated and reported values), 250 while another 23 lakes were removed because of suspicious problematic $T P_{\text {lake }}(5 \%$ outliers in 251 the ratio of $T P_{\text {out }}$ and $\left.T P_{\text {lake }}\right)$. Seventy-one lakes did not have data for $T P_{\text {in }}$ and 149 lakes without 252 data for $T P_{\text {lake }}$ were also removed. Next, 5 lakes with a surface area greater than $10,000 \mathrm{~km}^{2}(4$ 253 Laurentian Great Lakes and Lake Winnipeg in Canada) were excluded. Lake Tahoe in Nevada, 254 US, was also removed since its retention time $\left(\tau_{w}=700\right.$ yrs $)$ is 11 times larger than the second 255 largest lake in the database ( $\tau_{w}=60$ yrs for Lake Okanagan in British Columbia, Canada).

256 Considering that the net annual $\mathrm{TP}$ retention in lakes is assumed to be positive (i.e. $T P_{\text {out }}=$ $257 T P_{\text {lake }}<T P_{\text {in }}$ ) (Hamilton et al., 2018), about $10 \%$ of the lakes had negative $R_{T P}$ values. A negative $258 R_{T P}$ value may result from: 1) a lake is in transient condition after external loading reduction but 259 not in steady-state condition as static models assume (Jensen et al., 2006); 2) a lake receives 260 persistent internal P loading from the sediment (Søndergaard et al., 2013); and/or 3) the 261 measurements of $T P_{\text {in }}$ and $T P_{\text {lake }}$ have errors due to short water retention time of a lake (Brett and 262 Benjamin, 2008). Considering that the errors resulting in negative TP retention probably spread 263 through the whole database, we decided to follow the same practice as Brett and Benjamin (2008) 
264 to retain most of the lakes with negative $R_{T P}$. Hence, only 9 lakes with $R_{T P}<-0.85$ were 265 excluded from the database. Eventually, 738 observations (348 natural and 390 artificial lakes) 266 remained in the database (Fig. 1). All lakes are located in the northern hemisphere between latitude $25^{\circ}-60^{\circ} \mathrm{N}$, specifically in Europe and North America.

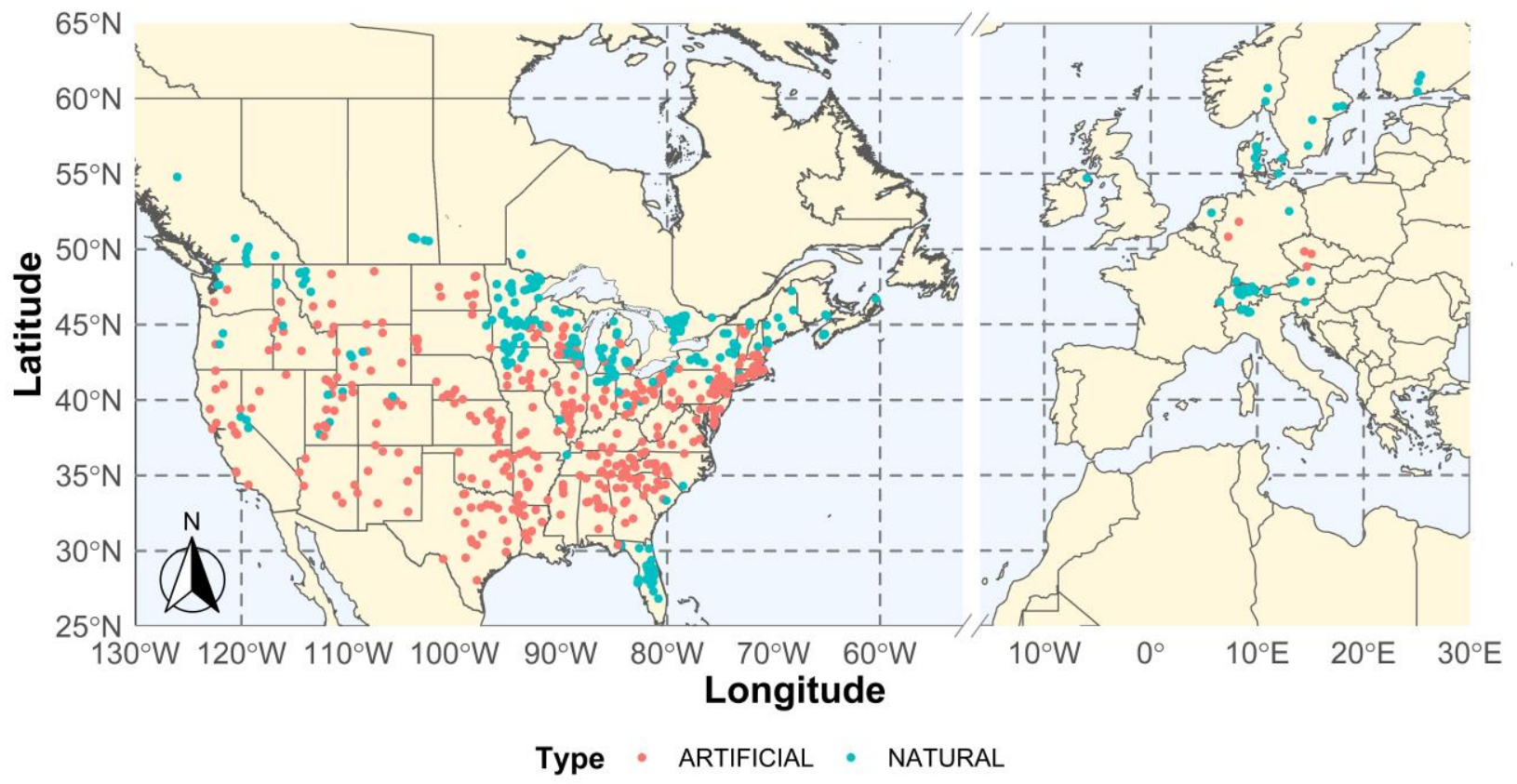

269 Figure 1. A representation of the data points $(n=738)$ in the database.

270 While some lakes have more than one measurement in the database, stating the number of lakes

271 with repeated measurement is a subjective issue. For example, Lake Sammamish in Washington

272 has three different measurements from three different surveys. However, for some lakes, e.g., Lake

273 Memphremagog in Quebec and Lake Päijänne in Finland, the whole lake basin is divided into

274 several sub-basins and each sub-basin is considered as a different observation data point in the 275 original databases. As a result, we refrain from the differentiation between the number of 276 observations and that of individual lakes and consider each data point as independent. 
277 The probability density distribution plot of six characteristics, i.e., water retention time, $T P_{i n}$, $278 T P_{\text {lake }}$, lake surface area, mean depth, and TP retention are shown in Fig. 2. Although the number 279 of natural lakes is slightly smaller than artificial lakes, they both cover a wide range of 280 hydroclimate and landscape characteristics. Generally, artificial lakes have relatively narrower 281 ranges with $T P_{i n}, T P_{\text {lake }}$, lake surface area, and mean depth than natural lakes, while their mean 282 values of $T P_{\text {in }}, T P_{\text {lake }}$, and lake surface area are higher than in natural lakes. Though the water 283 retention time of artificial lakes tends to be significantly smaller than that of natural lakes, the TP 284 retention of natural and artificial lakes seems to follow a similar distribution. The mean depth of 285 artificial and natural lakes is also quite similar. Table S1 presents the extremum and the measures 286 of the central tendency of the database variables. 


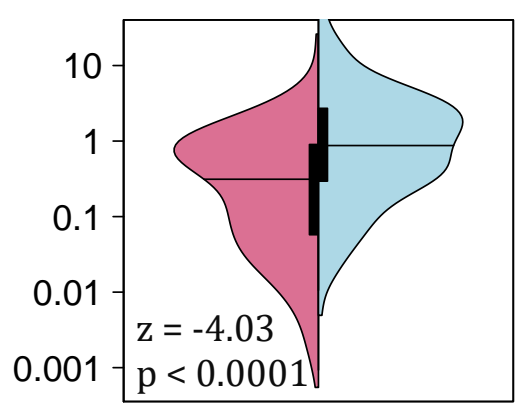

Water Retention (yr)

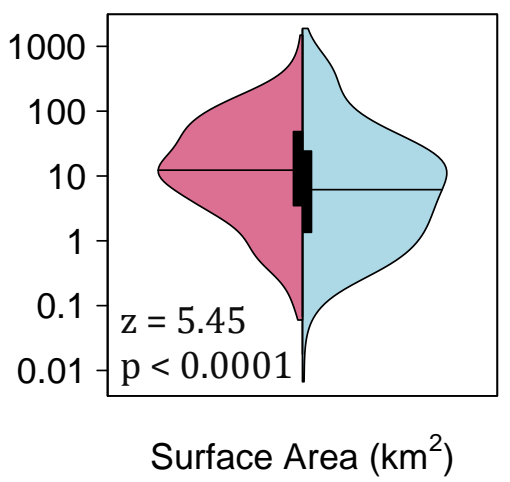
$R_{T P}$ values are not log-transformed.

\section{Results and Discussion}

\section{Appendix 1.}

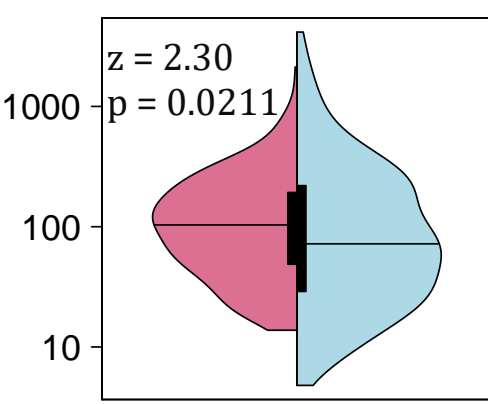

$$
\mathrm{TP}_{\mathrm{in}}\left(\mathrm{mgP} \mathrm{m}^{-3}\right)
$$

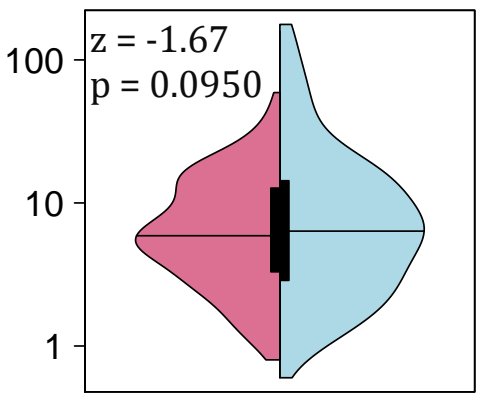

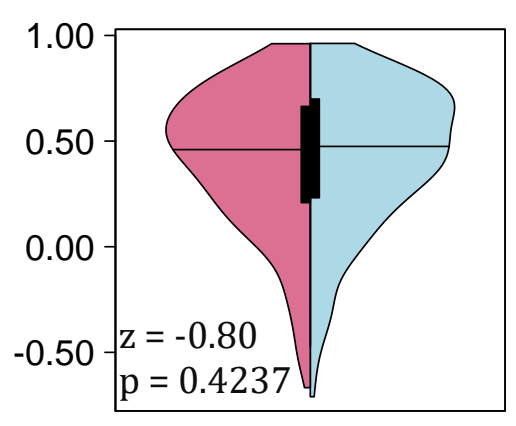

TP Retention

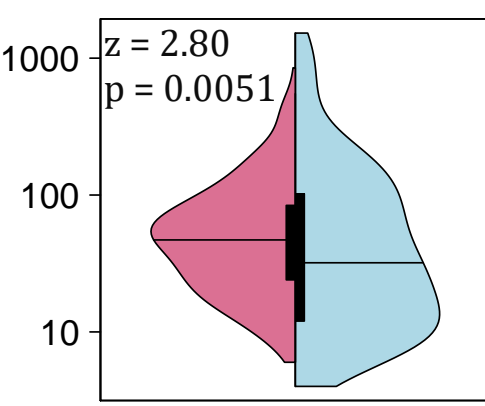

$\mathrm{TP}_{\text {lake }}\left(\mathrm{mgP} \mathrm{\textrm {m } ^ { - 3 } )}\right.$

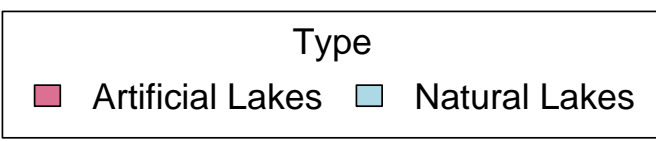

Figure 2. The probability density distribution of lake characteristics for the database divided by artificial or natural lakes. The black lines represent the box plots. The z-score (z) and p-value (p) of the two-tailed hypothesis test is carried out on the log-transformed data of water retention, $T P_{\text {in }}, T P_{\text {lake }}$, lake surface area, mean depth, while the

This section presents the results of the models' calibration and comparison of different hypotheses

followed by a comparison of the best performing models and a discussion on the retention of $\mathrm{P}$ in

different models. For the explanation of the Bayesian Information Criterion (BIC) used to make

the comparison between different hypotheses as well as between models the reader is referred to 
Table 5. Final goodness of fit results for the mechanistic, semi-mechanistic, strictly-empirical. The intra-type $\triangle B I C$ is the difference to the minimum $B I C$ within one type of models and the overall $\triangle B I C$ is the comparison to the minimum of all 39 models (See Appendix 1). Please note that in each model type, the best model(s) is(are) highlighted.

303 The overall best model(s) is(are) also highlighted in the last column.

\begin{tabular}{|c|c|c|c|c|c|c|c|c|c|}
\hline $\begin{array}{l}\text { Overall } \\
\text { Model } \\
\text { No. }\end{array}$ & & $\begin{array}{l}\text { Intratype } \\
\text { Model } \\
\text { No }\end{array}$ & Calibrated Parameters & ESS & $\mathrm{n}$ & $\mathrm{R}_{\text {adj }}^{2}$ & BIC & $\begin{array}{l}\text { Intratype } \\
\Delta \mathrm{BIC}\end{array}$ & $\begin{array}{l}\text { Overall } \\
\Delta \mathrm{BIC}\end{array}$ \\
\hline 1 & & 1 & $k_{1}=1.029 \pm 0.097$ & 76.44 & 1 & 0.578 & -1666.8 & 398 & 440 \\
\hline 2 & & 2 & $k_{1}=7.318 \pm 0.680$ & 79.91 & 1 & 0.559 & -1634.0 & 431 & 473 \\
\hline 3 & & 3 & $\alpha=0.566 \pm 0.021, k_{1}=0.242 \pm 0.061$ & 55.54 & 2 & 0.693 & -1895.9 & 169 & 211 \\
\hline 4 & $\widehat{ح}$ & 4 & $\alpha=0.563 \pm 0.016, k_{1}=1.890 \pm 0.275$ & 55.98 & 2 & 0.690 & -1890.0 & 175 & 217 \\
\hline 5 & $\frac{\pi}{\pi}$ & 5 & $k_{1}=0.019 \pm 0.002$ & 61.16 & 1 & 0.662 & -1831.3 & 233 & 276 \\
\hline 6 & $\underbrace{\sigma}$ & 6 & $k_{1}=0.090 \pm 0.013$ & 78.90 & 1 & 0.564 & -1643.4 & 421 & 464 \\
\hline 7 & 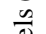 & 7 & $\alpha=0.620 \pm 0.019, k_{1}=0.008 \pm 0.002$ & 47.86 & 2 & 0.735 & -2005.7 & 59 & 101 \\
\hline 8 & $\frac{8}{8}$ & 8 & $\alpha=0.560 \pm 0.017, k_{1}=0.024 \pm 0.006$ & 55.21 & 2 & 0.695 & -1900.3 & 164 & 207 \\
\hline 9 & $\Sigma$ & 9 & $k_{1}=0.786 \pm 0.070$ & 68.80 & 1 & 0.620 & -1744.5 & 320 & 362 \\
\hline 10 & $\mathscr{Z}$ & 10 & $k_{1}=5.816 \pm 0.513$ & 72.76 & 1 & 0.598 & -1703.1 & 362 & 404 \\
\hline 11 & $\stackrel{m}{\Xi}$ & 11 & $\alpha=0.597 \pm 0.021, k_{1}=0.207 \pm 0.044$ & 53.62 & 2 & 0.703 & -1921.9 & 143 & 185 \\
\hline 12 & $\frac{\pi}{0}$ & 12 & $\alpha=0.582 \pm 0.017, k_{1}=1.390 \pm 0.222$ & 55.37 & 2 & 0.694 & -1898.1 & 167 & 209 \\
\hline 13 & $\sum^{\infty}$ & 13 & $k_{1}=0.027 \pm 0.003$ & 48.73 & 1 & 0.731 & -1999.0 & 66 & 108 \\
\hline 14 & & 14 & $k_{1}=0.148 \pm 0.019$ & 63.90 & 1 & 0.647 & -1799.0 & 266 & 308 \\
\hline 15 & & 15 & $\alpha=0.702 \pm 0.024, k_{1}=0.011 \pm 0.002$ & 44.18 & 2 & 0.756 & -2064.7 & $0^{*}$ & 42 \\
\hline 16 & & 16 & $\alpha=0.605 \pm 0.020, k_{1}=0.032 \pm 0.008$ & 52.85 & 2 & 0.708 & -1932.5 & 132 & 174 \\
\hline 17 & & 1 & $k_{1}=2.038 \pm 0.077, k_{2}=0.311 \pm 0.024$ & 48.54 & 2 & 0.732 & -1995.3 & 112 & 112 \\
\hline 18 & & 2 & $\begin{array}{l}k_{1}=0.531 \pm 0.076, k_{2}=0.307 \pm 0.023 \\
k_{3}=0.296 \pm 0.031\end{array}$ & 41.86 & 3 & 0.768 & -2098.0 & 9 & 9 \\
\hline 19 & $\widehat{ح}$ & 3 & $\begin{array}{l}k_{1}=0.324 \pm 0.078, k_{2}=0.263 \pm 0.024 \\
k_{3}=0.344 \pm 0.038, k_{4}=0.137 \pm 0.048\end{array}$ & 41.18 & 4 & 0.772 & -2103.5 & 3 & 3 \\
\hline 20 & 光 & 4 & $k_{1}=0.026 \pm 0.002, k_{2}=0.501 \pm 0.048$ & 52.19 & 2 & 0.711 & -1941.8 & 165 & 165 \\
\hline 21 & $\underbrace{\overparen{E}}_{\infty}$ & 5 & $\begin{array}{l}k_{1}=0.535 \pm 0.106, k_{2}=0.432 \pm 0.031 \\
k_{3}=-0.578 \pm 0.044\end{array}$ & 41.76 & 3 & 0.769 & -2099.8 & 7 & 7 \\
\hline 22 & $\frac{n}{\frac{a}{0}}$ & 6 & $\begin{array}{l}k_{1}=0.261 \pm 0.086, k_{2}=0.369 \pm 0.033 \\
k_{3}=-0.507 \pm 0.053, k_{4}=0.202 \pm 0.066\end{array}$ & 41.06 & 4 & 0.772 & -2105.7 & $1^{*}$ & $1 * *$ \\
\hline 23 & 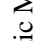 & 7 & $k_{1}=1.354 \pm 0.062, k_{2}=0.371 \pm 0.028$ & 48.53 & 2 & 0.732 & -1995.5 & 111 & 111 \\
\hline 24 & . & 8 & $\begin{array}{l}k_{1}=0.269 \pm 0.046, k_{2}=0.366 \pm 0.026 \\
k_{3}=0.356 \pm 0.037\end{array}$ & 41.81 & 3 & 0.768 & -2098.9 & 8 & 8 \\
\hline 25 & 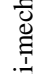 & 9 & $\begin{array}{l}k_{1}=0.149 \pm 0.042, k_{2}=0.313 \pm 0.028 \\
k_{3}=0.414 \pm 0.045, k_{4}=0.166 \pm 0.056\end{array}$ & 41.13 & 4 & 0.772 & -2104.4 & 3 & 3 \\
\hline 26 & $\overline{\mathrm{z}}$ & 10 & $k_{1}=0.030 \pm 0.002, k_{2}=0.623 \pm 0.050$ & 45.24 & 2 & 0.750 & -2047.3 & 60 & 60 \\
\hline 27 & מ & 11 & $\begin{array}{l}k_{1}=0.257 \pm 0.067, k_{2}=0.575 \pm 0.042 \\
k_{3}=-0.432 \pm 0.058\end{array}$ & 41.72 & 3 & 0.769 & -2100.4 & 7 & 7 \\
\hline 28 & & 12 & $\begin{array}{l}k_{1}=0.095 \pm 0.041, k_{2}=0.489 \pm 0.043 \\
k_{3}=-0.333 \pm 0.071, k_{4}=0.288 \pm 0.088\end{array}$ & 40.99 & 4 & 0.773 & -2106.9 & $0 *$ & $0 * *$ \\
\hline 29 & & 13 & $k_{1}=0.008 \pm 0.002, k_{2}=0.104 \pm 0.046$ & 43.49 & 2 & 0.759 & -2076.3 & 31 & 31 \\
\hline 30 & & 1 & $\begin{array}{l}k_{1}=0.257 \pm 0.067, k_{2}=0.575 \pm 0.042 \\
k_{3}=-0.432 \pm 0.058\end{array}$ & 53.27 & 3 & 0.705 & -1920.1 & 173 & 187 \\
\hline 31 & $\frac{\sqrt{0}}{\frac{\pi}{\pi}}$ & 2 & $\begin{array}{l}k_{1}=0.367 \pm 0.061, k_{2}=0.948 \pm 0.462 \\
k_{3}=0.571 \pm 0.060, k_{4}=0.006 \pm 0.002\end{array}$ & 53.40 & 4 & 0.704 & -1911.7 & 182 & 195 \\
\hline 32 & $=$ & 3 & $k_{1}=45.180 \pm 8.209, k_{2}=67.493 \pm 14.035$ & 54.38 & 2 & 0.699 & -1911.4 & 182 & 196 \\
\hline 33 & $\frac{2}{8}$ & 4 & $k_{1}=0.569 \pm 0.010, k_{2}=0.079 \pm 0.004$ & 48.83 & 2 & 0.730 & -1990.9 & 103 & 116 \\
\hline 34 & $\sum^{0}$ & 5 & $k_{1}=0.727 \pm 0.016, k_{2}=0.081 \pm 0.006$ & 52.88 & 2 & 0.708 & -1932.1 & 161 & 175 \\
\hline 35 & $\sum$ & 6 & $k_{1}=1.729 \pm 0.113, k_{2}=0.823 \pm 0.018$ & 42.50 & 2 & 0.765 & -2093.4 & $0 *$ & 14 \\
\hline 36 & 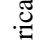 & 7 & $k_{1}=0.814 \pm 0.029, k_{2}=0.898 \pm 0.061$ & 48.76 & 2 & 0.730 & -1992.0 & 101 & 115 \\
\hline 37 & 节 & 8 & $\begin{array}{l}k_{1}=1.857 \pm 0.172, k_{2}=0.816 \pm 0.020 \\
k_{3}=0.891 \pm 0.057\end{array}$ & 42.40 & 3 & 0.765 & -2088.4 & 5 & 19 \\
\hline 38 & 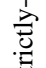 & 9 & $\begin{array}{l}k_{1}=0.971 \pm 0.079, k_{2}=0.809 \pm 0.020 \\
k_{3}=-0.170 \pm 0.010\end{array}$ & 42.56 & 3 & 0.764 & -2085.8 & 8 & 21 \\
\hline 39 & $\ddot{n}$ & 10 & $\begin{array}{l}k_{1}=0.244 \pm 0.042, k_{2}=0.161 \pm 0.020 \\
k_{3}=0.169 \pm 0.009\end{array}$ & 42.60 & 3 & 0.764 & -2085.1 & 8 & 22 \\
\hline
\end{tabular}


307 The BIC estimate of mechanistic models (model \#1-16 in Table 5) is used for the pairwise 308 comparison of the different hypotheses underlying the models. These comparisons include the 309 particle settling approach versus volumetric reaction approach; the hypothesis that lakes behave as 310 a plug-flow reactor versus a mixed flow reactor; the first-order reaction of phosphorus in lakes 311 versus the second-order reaction; and the hypothesis that a constant fraction of input phosphorus 312 participates in the reactions inside the lake versus the hypothesis that all the input phosphorus goes 313 under the same loss reactions. Fig. 5 presents the results of the pairwise comparison of the different 314 hypotheses. The BIC estimate of model \#15 $\left(R_{a d j}^{2}=0.756\right)$ suggests that it is the best mechanistic 315 model. The pairwise comparison of the hypotheses that are used for the development of models, 316 as presented below, shows that the hypotheses underlying model \#15 also outperform their 317 competitors. 

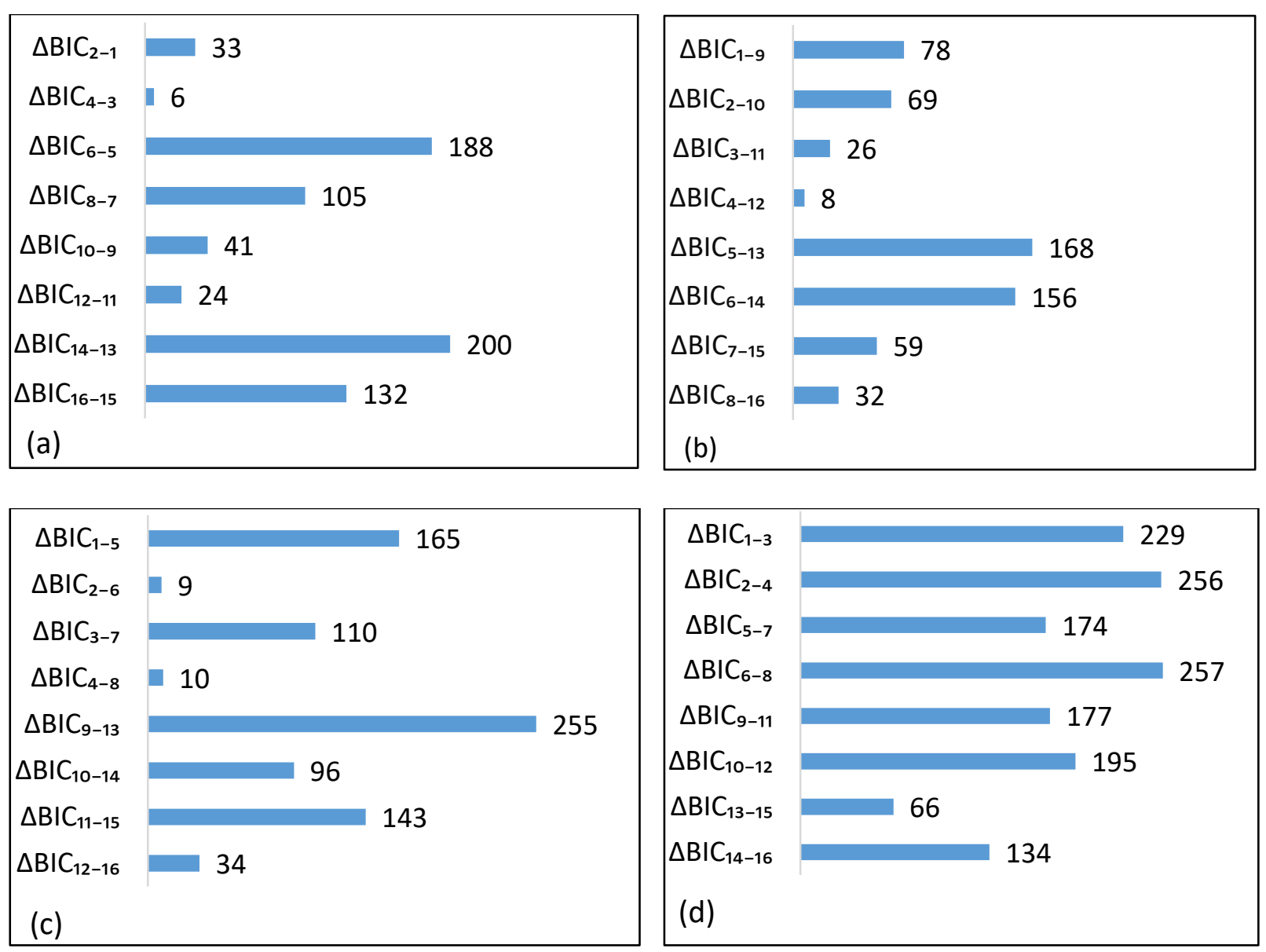

Figure 5. The pairwise comparison of mechanistic models considering their underlying hypotheses using $\triangle B I C$ values. (a) Comparison of settling velocity approach versus the volumetric reaction approach, (b) comparison of the plugflow hypothesis versus the mixed-flow hypothesis, (c) comparison of first-order reaction hypothesis versus the secondorder reaction hypothesis, and (d) comparison of the hypothesis that all input TP participates in the reactions versus the hypothesis that a fixed proportion of input TP participates in reactions.

As shown in Fig. 5a, the volumetric reaction approach for simulating TP performs better than the particle settling approach in all of the comparisons. Brett and Benjamin (2008) made a similar conclusion that their findings do not support the "widespread acceptance of the constant settling velocity model in the limnological literature". The volumetric loss rate of TP in model \#1 is found to be equal to $k_{1}=\sigma=0.786 \pm 0.070 y r^{-1}$ which is similar to the reported value of $\sigma=$ $0.65 y r^{-1}$ by Jones and Bachman (1976) but larger than the $\sigma=0.45 \pm 0.04 y r^{-1}$ reported by 
335 Brett and Benjamin (2008) and smaller than $\sigma=4.09 y r^{-1}$ reported by Walker (1985). Generally 336 the value of first-order volumetric loss rate of TP in mixed-flow models are found to be between $3370.1 y r^{-1}$ and $1 y r^{-1}$ (Vollenweider, 1976).

338 Even though our results do not support the particle settling approach, reporting the settling 339 velocities and comparing them with the literature might be of use for other modeling purposes. 340 The apparent settling velocity in a mixed-flow reactor (model \#2) is calibrated to $k_{1}=v=$ $3415.816 \pm 0.513 m_{y r^{-1}}$ which is very comparable to $v=5.1 \pm 0.6 m y r^{-1}$ reported by Brett and

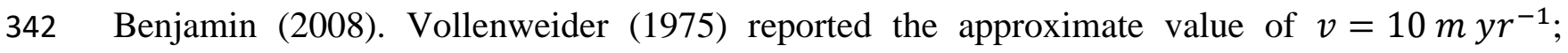
343 however, these values depend on the database that is used for calibration and may significantly 344 vary. For instance, Higgins and Kim (1981) argue that the Vollenweider's settling velocity of 10 $345 m y r^{-1}$ is for natural lakes and for a database of 10 Tennessee Valley Authority reservoirs with 346 $T P_{\text {in }}>25 \mathrm{mgTP}^{-3}$, they found the average settling velocity $v=92 \mathrm{~m} \mathrm{yr}^{-1}$.

\subsubsection{Plug flow reactor vs. mixed flow reactor}

348 Based on the $\triangle B I C$ values (Fig. 5b), there is strong to very strong evidence that the mixed-flow reactor hypothesis performs better than the plug-flow reactor hypothesis. In the literature, we found only two studies that consider or compare these two hypotheses. Although Higgins and Kim (1981) seem to be the first researchers proposing the use of the plug-flow model, they did not perform a

352 full comparison between the two models and postponed it to a later occasion, when more data 353 become available. They only discussed that the plug-flow model should be more appropriate for 354 long and narrow reservoirs. Walker (1985) compared the plug-flow and mixed-flow models for 60 355 reservoirs and concluded that the mixed-flow models perform better than plug-flow ones. Note 
357 the in-lake TP concentrations $\left(T P_{\text {lake }}\right)$ and made the same conclusion as that of Walker $(1985)$. In

358 the previous considerations of plug-flow and mixed-flow models, the numerical value for loss rate

359 or settling velocity of plug-flow models is smaller than that of mixed-flow model counterparts,

360 while in this analysis the P removal coefficients of plug-flow models are slightly larger than that

361 of mixed-flow models. For example, the first-order volumetric loss rate found by Walker (1985)

362 is $\sigma=4.09 y r^{-1}$ for mixed-flow model and $\sigma=1.66 y r^{-1}$ for plug-flow model. In this analysis,

363 these values are $\sigma=0.786 y r^{-1}$ and $\sigma=1.029 y r^{-1}$, respectively. This seems to be due to the

364 fact that while $T P_{\text {lake }}$ and $T P_{\text {out }}$ are not significantly different $(p<0.00001, n=540)$, the

365 formulae of the plug-flow model for $T P_{\text {out }}$ and $T P_{\text {lake }}$ differ from each other. The ambiguity in

366 which form of the plug-flow model should be used can be another reason that the plug-flow models

367 are less reliable.

\subsubsection{First-order vs. second-order reactions}

369 As presented in Fig. 5c, second-order reaction models are found to be better than first-order 370 reaction models. Using the data of only 4 alpine lakes and observing a linear relationship between

$371 T P_{\text {lake }}$ and their annual sedimentation, Vollenweider (1969) hypothesized the removal of TP as a

372 first-order reaction, henceforth making this hypothesis widely accepted. However, similar to

373 Walker (1985), our results show that assuming TP removal as a second-order function of TP $P_{\text {lake }}$

374 is performing better. The second-order volumetric loss rate of mixed-flow model in our study is

$375 k_{1}=\sigma_{2}=0.027 \pm 0.003 \mathrm{~m}^{3} \mathrm{mgTP}^{-1} \mathrm{yr}^{-1}$, which is smaller than $\sigma_{2}=0.10 \mathrm{~m}^{3} \mathrm{mgTP}^{-1} \mathrm{yr}^{-1}$

376 in Walker (1985). It is noteworthy to mention that the use of the second-order reaction models

377 does not add to the number of unknown parameters while increasing the prediction power. Another

378 difference between first-order and second-order models is that the second-order reaction model

379 associates the TP retention not only with average water retention time but also with $T P_{i n}$. The 
380 conventional approach for the calculation of $R_{T P}$ is the substitution of the developed models for $381 T P_{\text {lake }}$ into Eq. (8) instead of $T P_{\text {out }}$. In the first-order reaction models, the $T P_{\text {in }}$ is canceled in the 382 calculation of $R_{T P}$. For example, the $R_{T P}$ for model \#9 is as follows:

$$
R_{T P}=1-\frac{T P_{\text {lake }}}{T P_{\text {in }}}=1-\frac{T P_{\text {in }} /\left(1+\sigma \tau_{w}\right)}{T P_{\text {in }}}=\frac{\sigma \tau_{w}}{1+\sigma \tau_{w}}
$$

383 As seen in Eq. (19), $R_{T P}$ under the hypothesis of the first-order reaction only depend on the loss 384 rate constant and water retention time. If the loss rate is assumed to be constant but not a function 385 of $T P_{i n}$, this independency of $R_{T P}$ and $T P_{\text {in }}$ can be doubtable (Søndergaard et al., 2013). 386 Tammeorg et al. (2018) also show that $T P_{\text {in }}$ is an important factor affecting the retention of $\mathrm{TP}$ in 387 Finnish lakes. In second-order reaction hypothesis, $T P_{i n}$ still remains in the $R_{T P}$ equation. The $R_{T P}$ 388 estimates by the first-order reaction model (model \#9) and the second-order reaction model (model $389 \# 13$ ) are presented in Figs. 6a and 6b. The $R_{T P}$ in model \#13 is a surface that is dependent on $T P_{\text {in }}$ 390 and $\tau_{w}$. Therefore, while the model \#9 is able to predict about $20 \%$ of variability of $R_{T P}$, model $391 \quad$ \#13 improves to $26 \%$. 

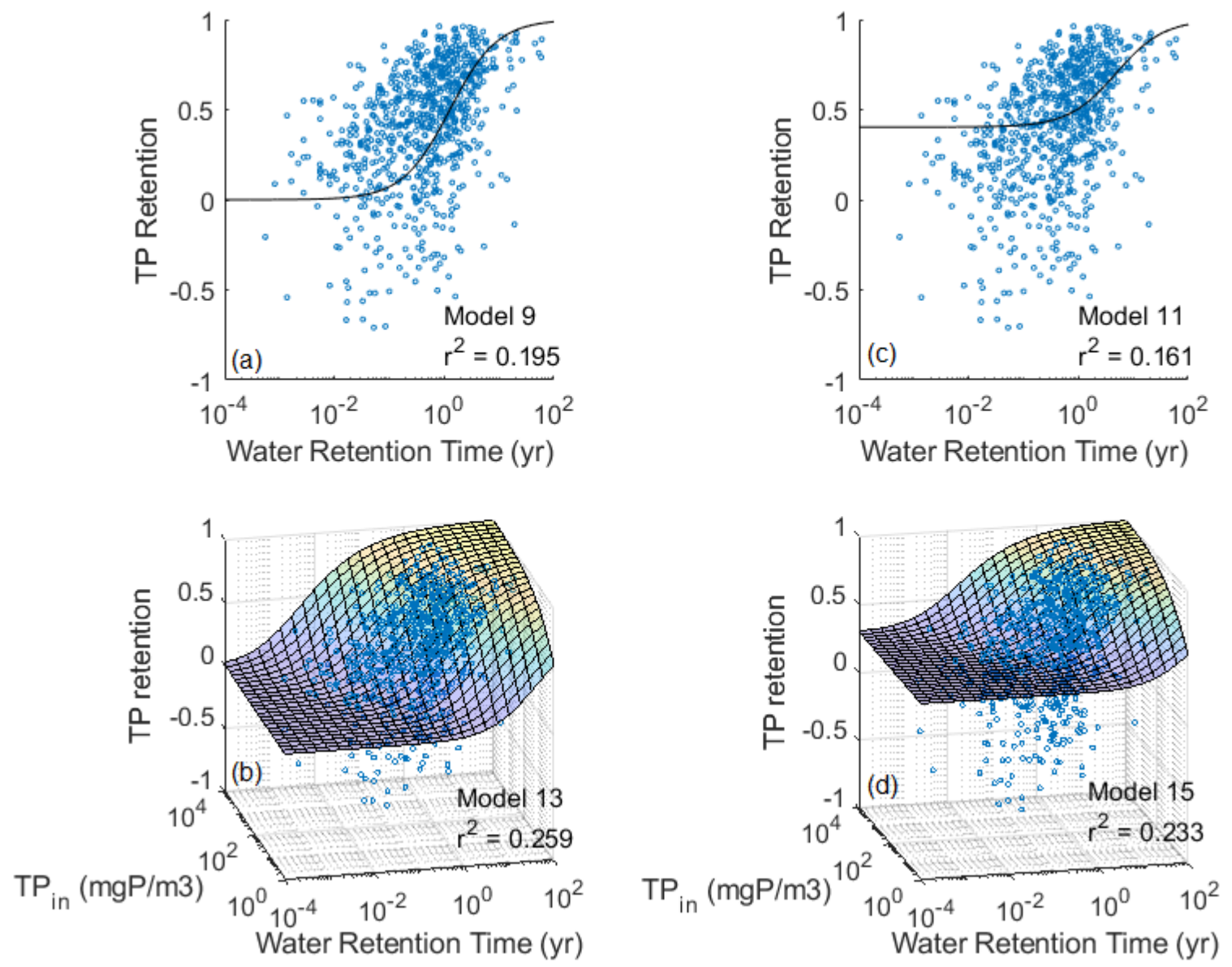

Figure 6. The measured and simulated TP retention using four different models. All models are from the mechanistic type and utilize the volumetric loss rate in a mixed-flow reactor hypothesis. Panel (a) shows the first-order model results for $R_{T P}$, panel (b) shows the second-order model results for $R_{T P}$. Panels (c) and (d) are respectively similar to panels (a) and (b) except that they utilize the hypothesis that $(1-\alpha) \%$ of the TP loading is fast settling particles that settle down in the lake inlet and do not participate in reactions.

\subsubsection{Rapid sedimentation fraction}

As presented in Fig. 5d, there is always very strong evidence that considering the fraction of rapid sedimentation generates better models. The TP removal coefficients in the models considering $\alpha$ fraction are smaller than those in the models without considering rapid sedimentation. This is because when considering $\alpha$-fraction, a portion $(1-\alpha)$ of the input of TP is removed at the 
entrance of the lake and does not participate in the reactions. The values previously used for $\alpha$ are respectively $\alpha=0.84$ (Jones and Bachmann, 1976), $0.49<\alpha<0.80$ (Canfield and Bachmann, 1981), $\alpha=0.50$ (Chapra, 1982), $\alpha=0.754 \pm 0.023$ (Prairie, 1989), and $\alpha=0.65 \pm 0.03$ (Brett and Benjamin, 2008). Based on our analysis (Table 5), the mean value of $\alpha$ generally ranges from 0.55 to 0.70 , depending on the choices of other hypotheses. It indicates that a significant proportion $409(30-45 \%)$ of the TP loading into the lakes may be removed rapidly and the rest reaches to main 410 basin of the lake. The TP removal coefficients for the remaining P loading is smaller than that for 411 the total loading and their value is generally between $20 \%$ and $45 \%$ of the original coefficients, as 412 shown in Fig. S1. Using the constant $\alpha$-fraction hypothesis forces a minimum value to the 413 simulated $R_{T P}$, regardless of the lake morphologic characteristics. The $R_{T P}$ under this hypothesis 414 will always be $R_{T P} \geq(1-\alpha)$ which can be seen as an upward shift in simulated $R_{T P}$ toward 415 higher values, especially in lakes with lower water retention time (Figs. 6b and 6d). This shift 416 results in an overestimation of $R_{T P}$ in lakes with water retention time smaller than a month. As 417 shown in Fig. 6, the predictive power of $R_{T P}$ in models that utilize $\alpha$-fraction hypothesis, is reduced 418 in comparison to their counterpart models without $\alpha$-fraction hypothesis. Although model \#9 and $419 \quad \# 13$ can respectively predict $20 \%$ and $26 \%$ of variation in $R_{T P}$ values, their $\alpha$-fraction counterparts, 420 i.e., models \#11 and \#15 can predict 16\% and 23\% respectively. However, models \#11 and \#15, 421 respectively perform about $2 \%$ and $8 \%$ better than models \#9 and \#13 in predicting the variation 422 of $T P_{\text {lake }}$. 


\subsection{Mechanistic, Semi-mechanistic, or Strictly-empirical Models?}

427 Using the $\triangle B I C<2$ criterion, the best intratype as well as the best overall models are chosen.

428 Among the mechanistic group, the mixed-flow, second-order, constant loss rate for constant $\alpha$ 429 fraction of $T P_{i n}$ model (model \#15) outperforms others. The second best in this group is model \#7 430 which has the same hypotheses as model \#15, except that the lake is assumed a plug-flow reactor. 431 However, with an intratype $\Delta B I C_{7-15}$ of 59 , there is very strong evidence that model \#15 is the 432 best mechanistic model.

433 Among the semi-mechanistic group, model \#28, with the form of a mixed reactor with a second434 order reaction rate estimated by $\tau_{w}, T P_{i n}$ and $\bar{z}$ is selected as the best model. However, with $435 \Delta B I C_{22-28}=1$, model \#22 which is the plug-flow reactor version of model \#28 is chosen as the 436 second-best model and comparable to model \#28. The fact that the first two best performing 437 models in both the mechanistic and the semi-mechanistic group utilize second-order hypothesis 438 merely emphasizes the importance of this hypothesis. With an intra-type $\triangle B I C$ of 3 , models \#25 439 and \#19 are the first-order reaction versions of models \#28 and \#22, respectively, which also use 440 a combination of $\tau_{w}, T P_{i n}$ and $\bar{z}$ for the estimation of the volumetric reaction rate. The next two 441 models \#27 and \#21 with $\triangle B I C$ equal to 7 also utilize the same hypotheses of models \#28 and \#22, 442 except that $\bar{z}$ is not used for the estimation of the TP loss rate. Generally, the performance of the 443 semi-mechanistic group is better than mechanistic models.

444 Among the strictly-empirical group, the recalibrated OECD model (model \#35) is selected as the 445 best performing and there is not any other candidate in this group with $\triangle B I C \leq 2$. The first five 446 models in this group (models \#30-34) use $R_{T P}$ for simulating $T P_{\text {lake }}$. Hence, there is a challenge 447 in calibrating these models because $R_{T P}$ might be estimated larger than one for some lakes, which 
448 will result in a negative prediction for $T P_{\text {lake }}$ (note that $T P_{\text {lake }}=T P_{\text {in }}\left(1-R_{T P}\right)$ ). Considering 449 that the $T P_{\text {lake }}$ values are log-transformed for the calculation of the estimated sum-of-errors $(E S S)$, 450 a penalty is applied for the unknown parameters that result in negative simulated $T P_{\text {lake }}$.

451 The overall comparison of the groups is also presented in Fig. 7. The semi-mechanistic models 452 generally outperform the other two types. The top 8 models are all from the semi-mechanistic 453 group, while the best performing outside of the semi-mechanistic group is the OECD model with 454 an overall $\triangle \mathrm{BIC}$ of 14 . The mechanistic models mainly rely on the assumptions to explain the 455 variation of $T P_{\text {lake }}$ without the privilege of the other two types to use statistical terms for 456 improving their prediction power. Hence, as shown in Fig. 7, the mechanistic models have a wider 457 range of $R_{a d j}^{2}$ in comparison to the other two types. The strictly-empirical models generally 458 perform better than the mechanistic group because they are not limited to the physical 459 representation of the system. The comparison of the semi-mechanistic and strictly-empirical 460 models also shows that generally, the semi-mechanistic models perform better than empirical 461 models with the same number of unknown parameters. This can be because semi-mechanistic 462 models have the form of a physical model, which helps them to better explain the changes in 463 comparison to their strictly-empirical counterparts. For example, models \#38 and \#39 are two 464 strictly-empirical models that use three parameters (i.e., $k_{1}, k_{2}$ and $k_{3}$ ) as well as two variables $465 T P_{\text {in }}$ and $\tau_{w}$. Semi-mechanistic models \#18,\#21, \#24, and \#27 have similar characteristics, except 466 that they have the form of physical models. The $\triangle B I C$ of these semi-mechanistic models and the 467 two similar strictly-empirical models is more than 10, indicating that in comparison there is very 468 strong evidence against the strictly-empirical models.

469 The performance of the best models from each type are presented in Fig. 8, including the simulated $470 T P_{\text {lake }}$ versus the measured $T P_{\text {lake }}$ as well as the relative errors of simulated $T P_{\text {lake }}$. While model 
$471 \quad \# 28$ has the highest $R_{a d j}^{2}$, the closest median of relative errors to one is observed in model \#22 and

472 the smallest Inter Quartile Range (IQR) which is the difference between the third and first quartile

473 is observed in model \#35. The distribution of the parameters of the best performing models is

474 presented in Fig. S2.

475

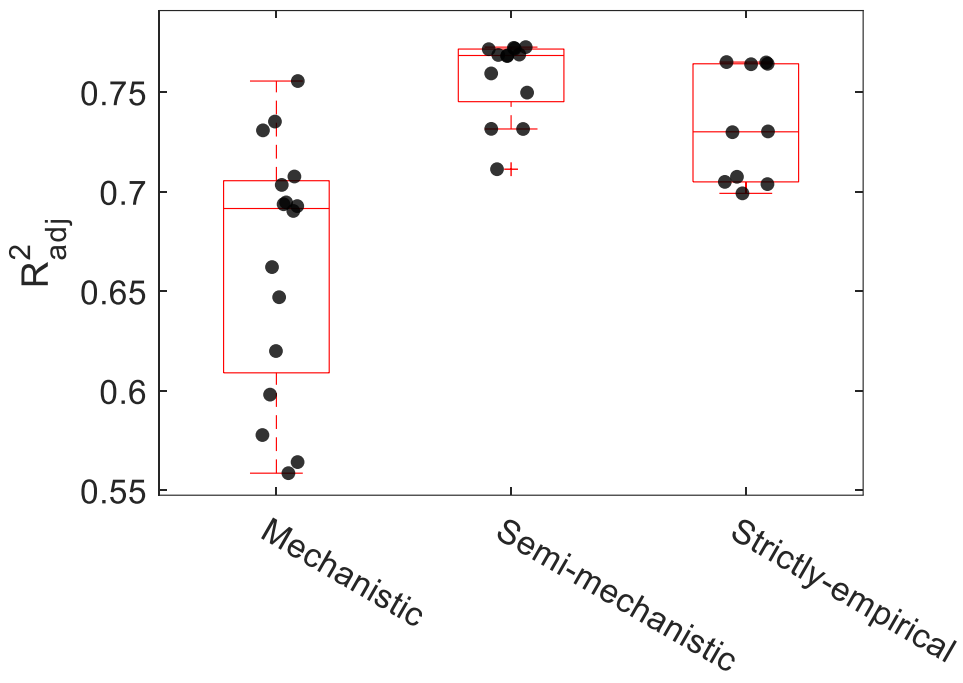

477 Figure 7. The $R_{a d j}^{2}$ values of the models grouped by the model types as mechanistic, semi-mechanistic, and strictly478 empirical models. 

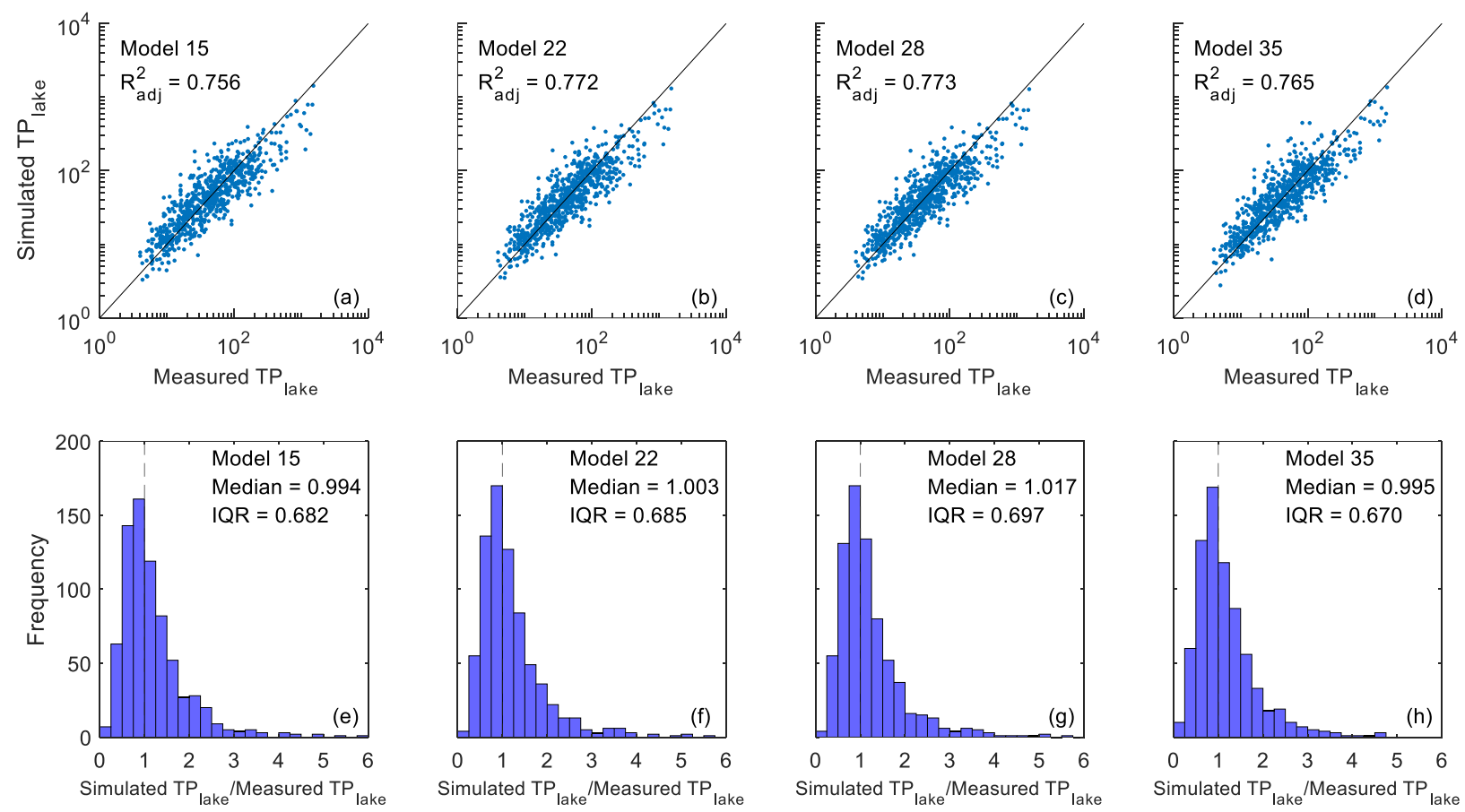

Figure 8. Observed lake TP concentrations plotted against the simulated lake TP concentration for the four best models in panels (a) to (d). The perfect fit is shown by using a diagonal line in these panels. The frequency distribution of the relative error of the four best models is also shown in panels (e) to (h) where the dashed line shows the perfect 1:1 fit. The median and the Inter Quartile Range (IQR) of the relative errors are also presented in the corresponding panels.

The comparison of the mechanistic and semi-mechanistic models performance shows that the use of constant values for the unknown parameters is a limitation for mechanistic models. Previous studies have shown correlations between the TP loss rate and the lake and landscape characteristics (Cheng and Basu, 2017; Hejzlar et al., 2006). The most prevailing type of relation between removal rate and lake characteristics in the literature is from Larsen and Mercier (1976) with the form of $\sigma=k_{1} \tau_{w}^{k_{2}}$ where $k_{2}$ has been repeatedly found to be around -0.5 by different researchers. This relationship implies that TP loss rate is proportional to the lake flushing rate $\left(\sigma \propto \rho^{0.5}\right)$. Canfield and Bachmann (1981) found it unclear that a higher flushing rate correlates to a higher sedimentation rate. They hypothesized that higher TP loading may accelerate algal growth and 
$k_{1}(L / \bar{z})^{k_{2}}$ which is equivalent to $\sigma \propto k_{1}\left(T P_{\text {in }} / \tau_{w}\right)^{k_{2}}$ they found $k_{2}$ is approximately equal to 0.5 which is in line with Larsen and Mercier (1976)'s assumption. Hejzlar (2006) showed the loss rate is correlated to all three $T P_{i n}, \tau_{w}$ and $\bar{z}$ and as shown in Table 5, all four best performing models are semi-mechanistic models whose TP removal rate is a function of these variables. The firstorder and second-order volumetric loss rate of model \#25 and \#28 are as follows:

$$
\begin{aligned}
& \sigma=0.149 \frac{\left(T P_{\text {in }}\right)^{0.414}(\bar{z})^{0.166}}{\left(\tau_{w}\right)^{0.687}} \\
& \sigma_{2}=0.095 \frac{(\bar{z})^{0.288}}{\left(\tau_{w}\right)^{0.511}\left(T P_{\text {in }}\right)^{0.333}}
\end{aligned}
$$

As seen, the first-order volumetric reaction rate is proportional to $T P_{\text {in }}$ while the second-order volumetric reaction rate is proportional to the inverse of $T P_{i n}$. While in the semi-mechanistic models, these rates are dynamically changed by different lake characteristics, in their mechanistic counterparts, only the constant values of $\sigma=0.786 y r^{-1}$ and $\sigma_{2}=0.027 \mathrm{~m}^{3} \mathrm{mgTP}^{-1} \mathrm{yr}^{-1}$ are used. The phosphorus loss term (i.e., $\sigma T P_{\text {lake }}$ for the first-order and $\sigma_{2} T P_{\text {lake }}^{2}$ for the second-order) for mixed-flow models using the constant and dynamic volumetric reaction rates is shown in Fig. 9. The comparison of Fig. 9a and 10b show that the mechanistic models, especially the first-order mechanistic model, have a limited range of TP loss prediction. This range, for the mechanistic first-order model, is between 3 and $1200 \mathrm{mgTP}^{-3} \mathrm{yr}^{-1}$ while the second-order mechanistic model is from 0.4 to $62000 \mathrm{mgTP}^{-3} \mathrm{yr}^{-1}$ the limited range of TP loss prediction in the firstorder hypothesis is solved when using the dynamic loss term calculation in the semi-mechanistic models, as the loss terms of first-order and second-order models in Fig. $9 \mathrm{~b}$ are similar. However, it is apparent that as the TP loss term increases (with the increase of lake TP concentration) the behavior of the TP loss term in first-order and second-order models slightly differ. The first-order 

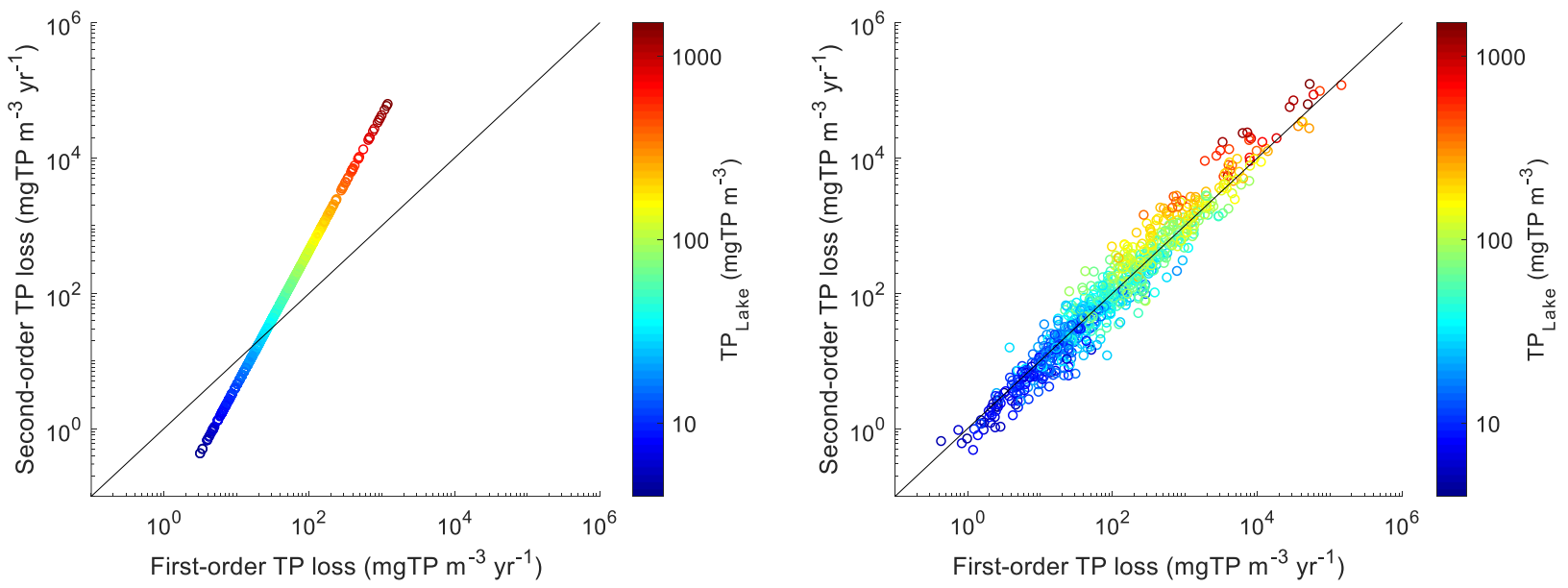

Figure 9. The comparison of the TP loss term (i.e., $\sigma T P_{\text {lake }}$ for the first-order and $\sigma_{2} T P_{\text {lake }}^{2}$ for the second-order hypothesis) for the mixed flow models. The first-order model TP loss term is plot versus the second-order model TP loss term. The loss term is shown for (a) the mechanistic models \#9 and \#13 and (b) the semi-mechanistic models \#25 and \#28.

\section{Conclusion}

The main objective of this paper was to assess four pairs of competing hypotheses that are suggested for retention of TP in lakes using a large database. For this reason, 16 mechanistic models are developed explicitly based on the physical representation of lakes. Specifically, this research found that the best performing mechanistic model considers the lake as a mixed-flow reactor where $30 \%$ of the input TP is rapidly settled in the entrance and the remaining participates in a second-order reaction over the volume of the lake. It is worth highlighting that the $\alpha$-fraction has been generally overlooked in previous studies and the combination of this hypothesis with second-order reaction hypothesis and plug-flow models is for the first time conducted in this study. Though the $\alpha$-fraction hypothesis is supported by the data, this fraction does not seem to be constant for all lakes and this hypothesis overestimates TP retention for lakes with relatively short 
535 water retention time (e.g., $\tau_{w}<1$ month). Estimation of $\alpha$-fraction as a function of the lake and 536 river characteristics should be further investigated in the future. Using the lake and river 537 characteristics to calculate the unknown parameter of the mechanistic model results in the 538 development of a semi-mechanistic model, which is found to be the best performing type. 539 Modeling the TP removal as a second-order reaction outperformed the first-order reaction models

540 both in mechanistic and semi-mechanistic groups. The well-known strictly-empirical models not 541 only failed to perform better than the tested semi-mechanistic models but also they do not 542 necessarily provide any information about the retention mechanism. The results of this study

543 provide more insight into the $\mathrm{P}$ retention in lakes and can be used for large-scale hydrological 544 models to simulate P cycle and assessment of lakes eutrophication status.

\section{Acknowledgment}

547 Helps from Dr. Michael Brett and Dr. Joseph Hejzlar in providing us with the lake database inputs 548 are kindly hereby acknowledged. Adam Grodek and Kevin Sandmaier revised an early version of 549 the manuscript for English writing.

$551 \quad$ Appendix 1: Statistical Analysis

552 The objective function of the fitting process is minimizing Error Sum-of-Squares (ESS) between 553 the $\log 10$-transformed $T P_{\text {lake }}$ observations and simulations (See Eq. A.1). We used the bootstrap 554 resampling method (sampling with replacement) to measure the accuracy of the fitted parameters. 555 The fitting process was repeated many times (1000 times in this study) and each time the used 556 database was a resampled dataset of the complete database $(n=738)$. Selection of the samples 
557 followed the uniform distribution and replacement was allowed (Efron, 1979). The calculation of

558 ESS and the adjusted coefficient of determination $\left(R_{a d j}^{2}\right)$ are as follows:

$$
\begin{aligned}
& E S S=\sum\left[\log _{10}\left(T P_{\text {lake } e_{\text {Observed }}}\right)-\log _{10}\left(T P_{\text {lake }_{\text {Predicted }}}\right)\right]^{2}=\sum\left(\log _{10} \frac{T P_{\text {lake }_{\text {Observed }}}}{T P_{\text {lake }_{\text {Predicted }}}}\right)^{2} \\
& R_{a d j}^{2}=1-\left(\frac{n-1}{n-p-1}\right) \frac{E S S}{T S S}
\end{aligned}
$$

559 where $n$ is the number of data points, $p$ is the number of unknown parameters in the model TSS is 560 the Total Sum-of-Squares of population defined as follows:

$$
T S S=\sum \log _{10}\left(T P_{\text {lake }_{\text {Observed }}} / \overline{T P_{\text {lake }} \text { observed }}\right)
$$

561 For finding the best models, the Bayesian Information Criterion (BIC) is used (Schwarz, 1978),

562 which take into account both the best fit and the number of calibrated parameters as follows:

$$
B I C=n \ln \left(\frac{E S S}{n}\right)+p \ln (n)
$$

563 As can be seen in this equation, larger errors in the simulation (ESS) as well as the greater number

564 of dependent variables $(p)$ increases BIC estimate. Hence, the minimum BIC value indicates the 565 best model. The difference between the BIC estimates $(\triangle B I C)$ is used to compare different models, 566 as follows:

$$
\Delta B I C_{i-j}=B I C_{i}-B I C_{j}
$$

567 where the $i$ and $j$ are the indicator number of the model and, in this paper, $j$ is the model of lower 568 BIC estimate, i.e., the better model. By using the similarity to the likelihood ratio testing statistics, 569 Kass and Raftery (1995) have suggested the values in Table A.1 to be used for describing the 570 evidence against the model with higher BIC as a better model. 
574

575

576

577

578

579

580

581

582

583

584

585

586

587

588

589

590

591

592

593

594

595

596

597

598

599

600

601

602

603

604
Table A.1. Guideline for the interpretation of the $\Delta B I C_{i-j}$ in the comparison of the models (adopted from Kass \& Raftery, 1995).

\begin{tabular}{ll}
\hline$\Delta B I C_{i-j}$ & Evidence against $i$ th model as a better model to the $j$ th model \\
\hline $0-2$ & Not worth more than a bare mention \\
$2-6$ & Positive \\
$6-10$ & Strong \\
$>10$ & Very strong \\
\hline
\end{tabular}

\section{References}

Abell, J.M., Özkundakci, D., Hamilton, D.P., van Dam-Bates, P., Mcdowell, R.W., 2019. Quantifying the Extent of Anthropogenic Eutrophication of Lakes at a National Scale in New Zealand. Environ. Sci. Technol. 53, 9439-9452. https://doi.org/10.1021/acs.est.9b03120

Braake, H.A.B. t., van Can, H.J.L., Verbruggen, H.B., 1998. Semi-mechanistic modeling of chemical processes with neural networks. Eng. Appl. Artif. Intell. 11, 507-515. https://doi.org/10.1016/S0952-1976(98)00011-6

Brett, M.T., Benjamin, M.M., 2008. A review and reassessment of lake phosphorus retention and the nutrient loading concept. Freshw. Biol. 53, 194-211. https://doi.org/10.1111/j.13652427.2007.01862.x

Bryhn, A.C., Håkanson, L., 2007. A Comparison of Predictive Phosphorus Load-Concentration Models for Lakes. Ecosystems 10, 1084-1099. https://doi.org/10.1007/s10021-007-9078-z

Canfield, D.E., Bachmann, R.W., 1981. Prediction of total phosphorus concentrations, chlorophyll a, and Secchi depths in natural and artificial lakes. Can. J. Fish. Aquat. Sci. 38, 414-423. https://doi.org/10.1139/f81-058

Chapra, S.C., 1982. A budget model accounting for the positional availability of phosphorus in lakes. Water Res. 16, 205-209. https://doi.org/10.1016/0043-1354(82)90112-9

Chapra, S.C., 1977. Total Phosphorus Model for the Great Lakes. J. Environ. Eng. Div. 103, 147-161. https://doi.org/10.1061/JEEGAV.0000609

Chapra, S.C., 1975. Comment on 'An empirical method of estimating the retention of phosphorus in lakes' by W. B. Kirchner and P. J. Dillon. Water Resour. Res. 11, 10331034. https://doi.org/10.1029/WR011i006p01033

Chapra, S.C., Reckhow, K.H., 1979. Expressing the Phosphorus Loading Concept in Probabilistic Terms. J. Fish. Res. Board Canada 36, 225-229. https://doi.org/10.1139/f79034

Chen, X., Xu, B., Zheng, Y., Zhang, C., 2019. Nexus of water, energy and ecosystems in the upper Mekong River: A system analysis of phosphorus transport through cascade reservoirs. 
Sci. Total Environ. 671, 1179-1191. https://doi.org/10.1016/j.scitotenv.2019.03.324

Cheng, F.Y., Basu, N.B., 2017. Biogeochemical hotspots: Role of small water bodies in landscape nutrient processing. Water Resour. Res. 53, 5038-5056. https://doi.org/10.1002/2016WR020102

Cooke, G.D., Welch, E.B., Peterson, S., Nichols, S.A., 2016. Restoration and Management of Lakes and Reservoirs, 3rd ed, Biomass. CRC Press. https://doi.org/10.1201/9781420032109

Deng, J., Li, Y., Xu, B., Ding, W., Zhou, H., Schmidt, A., 2020. Ecological Optimal Operation of Hydropower Stations to Maximize Total Phosphorus Export. J. Water Resour. Plan. Manag. 146, 04020075. https://doi.org/10.1061/(ASCE)WR.1943-5452.0001275

Dillon, P.J., 1974. A Critical Review of Vollenweider's Nutrient Budget Model and Other Related Models. J. Am. Water Resour. Assoc. 10, 969-989. https://doi.org/10.1111/j.17521688.1974.tb00617.x

Dillon, P.J., Kirchner, W.B., 1975. Reply [to "Comment on 'An empirical method of estimating the retention of phosphorus in lakes' by W. B. Kirchner and P. J. Dillon”]. Water Resour. Res. 11, 1035-1036. https://doi.org/10.1029/WR011i006p01035

Dillon, P.J., Molot, L.A., 1996. Long-term phosphorus budgets and an examination of a steadystate mass balance model for central Ontario lakes. Water Res. 30, 2273-2280. https://doi.org/10.1016/0043-1354(96)00110-8

Dillon, P.J., Rigler, F.H., 1974. The Phosphorus-Chlorophyll Relationship in Lakes. Limnol. Oceanogr. 19, 767-773. https://doi.org/10.4319/lo.1974.19.5.0767

Efron, B., 1979. Bootstrap Methods: Another Look at the Jackknife. Ann. Stat. https://doi.org/10.1214/aos/1176344552

Estalaki, S.M., Kerachian, R., Nikoo, M.R., 2016. Developing water quality management policies for the Chitgar urban lake: application of fuzzy social choice and evidential reasoning methods. Environ. Earth Sci. 75, 1-16. https://doi.org/10.1007/s12665-015-50654

Foy, R.H., 1992. A phosphorus loading model for northern Irish Lakes. Water Res. 26, 633-638. https://doi.org/10.1016/0043-1354(92)90238-Y

Gibson, G., Carlson, R., Simpson, J., Smeltzer, E., Gerritson, J., Chapra, S., Heiskary, S., Jones, J., Kennedy, R., 2000. Nutrient Criteria Technical Guidance Manual: Lakes and Reservoirs. EPA-822-B00-001. US Environmental Protection Agency. Washington, DC. Available at https://www.epa.gov/sites/production/files/2018-10/documents/nutrient-criteria-manuallakes-reservoirs.pdf (verified on 01 Apr. 2021).

Gobler, C.J., 2020. Climate Change and Harmful Algal Blooms: Insights and perspective. Harmful Algae 91, 101731. https://doi.org/10.1016/j.hal.2019.101731

Granéli, E., Weberg, M., Salomon, P.S., 2008. Harmful algal blooms of allelopathic microalgal species: The role of eutrophication. Harmful Algae 8, 94-102. https://doi.org/10.1016/j.hal.2008.08.011 
Hamilton, D.P., Collier, K.J., Quinn, J.M., Howard-Williams, C. (Eds.), 2018. Lake Restoration Handbook. Springer International Publishing, Cham. https://doi.org/10.1007/978-3-31993043-5

Heisler, J., Glibert, P.M., Burkholder, J.M., Anderson, D.M., Cochlan, W., Dennison, W.C., Dortch, Q., Gobler, C.J., Heil, C.A., Humphries, E., Lewitus, A., Magnien, R., Marshall, H.G., Sellner, K., Stockwell, D.A., Stoecker, D.K., Suddleson, M., 2008. Eutrophication and harmful algal blooms: A scientific consensus. Harmful Algae 8, 3-13. https://doi.org/10.1016/j.hal.2008.08.006

Hejzlar, J., Šámalová, K., Boers, P., Kronvang, B., 2006. Modelling Phosphorus Retention in Lakes and Reservoirs, in: The Interactions Between Sediments and Water. Springer Netherlands, Dordrecht, pp. 123-130. https://doi.org/10.1007/978-1-4020-5478-5_13

Hickey, C.W., Gibbs, M.M., 2009. Lake sediment phosphorus release management-Decision support and risk assessment framework. New Zeal. J. Mar. Freshw. Res. 43, 819-856. https://doi.org/10.1080/00288330909510043

Higgins, J.M., Kim, B.R., 1981. Phosphorus retention models for Tennessee Valley Authority reservoirs. Water Resour. Res. 17, 571-576. https://doi.org/10.1029/WR017i003p00571

Hu, W., Li, C., Ye, C., Wang, J., Wei, W., Deng, Y., 2019. Research progress on ecological models in the field of water eutrophication: CiteSpace analysis based on data from the ISI web of science database. Ecol. Modell. 410, 108779. https://doi.org/10.1016/j.ecolmodel.2019.108779

Imboden, D.M., 1974. Phosphorus model of lake eutrophication. Limnol. Oceanogr. 19, 297304. https://doi.org/10.4319/lo.1974.19.2.0297

Jensen, J.P., Pedersen, A.R., Jeppesen, E., Søndergaard, M., 2006. An empirical model describing the seasonal dynamics of phosphorus in 16 shallow eutrophic lakes after external loading reduction. Limnol. Oceanogr. 51, 791-800. https://doi.org/10.4319/lo.2006.51.1_part_2.0791

Jones, J.R., Bachmann, R.W., 1976. Prediction of phosphorus and chlorophyll levels in lakes. J. Water Pollut. Control Fed. 48, 2176-2182.

Jørgensen, S.E., Bendoricchio, G., 2011. Fundamentals of ecological modelling. Elsevier.

Jørgensen, S.E., Löffler, H., Rast, W., Straškraba, M., 2005. Lake and reservoir management. Elsevier.

Kasprzak, P., Gonsiorczyk, T., Grossart, H.-P., Hupfer, M., Koschel, R., Petzoldt, T., Wauer, G., 2018. Restoration of a eutrophic hard-water lake by applying an optimised dosage of polyaluminium chloride (PAC). Limnologica 70, 33-48. https://doi.org/10.1016/j.limno.2018.04.002

Kass, R.E., Raftery, A.E., 1995. Bayes Factors. J. Am. Stat. Assoc. 90, 773-795. https://doi.org/10.2307/2291091

Kazmierczak, J., Nilsson, B., Postma, D., Sebok, E., Karan, S., Müller, S., Czekaj, J., Engesgaard, P., 2021. Transport of geogenic phosphorus to a groundwater-dominated 
eutrophic lake. J. Hydrol. 126175. https://doi.org/10.1016/j.jhydrol.2021.126175

683

684

685

686

687

688

689

690

691

692

693

694

695

696

697

698

699

700

701

702

703

704

705

706

707

708

709

710

711

712

713

714

715

716

717

718

719

720
Khorasani, H., Kerachian, R., Malakpour-Estalaki, S., 2018. Developing a comprehensive framework for eutrophication management in off-stream artificial lakes. J. Hydrol. 562, 103-124. https://doi.org/10.1016/j.jhydrol.2018.04.052

Kirchner, W.B., Dillon, P.J., 1975. An empirical method of estimating the retention of phosphorus in lakes. Water Resour. Res. 11, 182-183.

https://doi.org/10.1029/WR011i001p00182

Kõiv, T., Nõges, T., Laas, A., 2011. Phosphorus retention as a function of external loading, hydraulic turnover time, area and relative depth in 54 lakes and reservoirs. Hydrobiologia 660, 105-115. https://doi.org/10.1007/s10750-010-0411-8

Larsen, D.P., Mercier, H.T., 1976. Phosphorus Retention Capacity of Lakes. J. Fish. Res. Board Canada 33, 1742-1750. https://doi.org/10.1139/f76-221

Le Moal, M., Gascuel-Odoux, C., Ménesguen, A., Souchon, Y., Étrillard, C., Levain, A., Moatar, F., Pannard, A., Souchu, P., Lefebvre, A., Pinay, G., 2019. Eutrophication: A new wine in an old bottle? Sci. Total Environ. https://doi.org/10.1016/j.scitotenv.2018.09.139

Lewis, W.M., Wurtsbaugh, W.A., 2008. Control of lacustrine phytoplankton by nutrients: Erosion of the phosphorus paradigm. Int. Rev. Hydrobiol. 93, 446-465. https://doi.org/10.1002/iroh.200811065

Liang, Z., Xu, Y., Qiu, Q., Liu, Y., Lu, W., Wagner, T., 2021. A framework to develop joint nutrient criteria for lake eutrophication management in eutrophic lakes. J. Hydrol. 594, 125883. https://doi.org/10.1016/j.jhydrol.2020.125883

Lorenzen, M.W., 1973. Predicting the effects of nutrient diversion on lake recovery, in: Middlebrooks, E.J., Falkenborg, D.H., Maloney, T.E. (Eds.), Modeling the Eutrophication Process: Workshop Proceedings. Logan, Utah, p. 228.

Lürling, M., Waajen, G., de Senerpont Domis, L.N., 2016. Evaluation of several end-of-pipe measures proposed to control cyanobacteria. Aquat. Ecol. 50, 499-519. https://doi.org/10.1007/s10452-015-9563-y

Maavara, T., Parsons, C.T., Ridenour, C., Stojanovic, S., Dürr, H.H., Powley, H.R., Van Cappellen, P., 2015. Global phosphorus retention by river damming. Proc. Natl. Acad. Sci. 112, 15603-15608. https://doi.org/10.1073/pnas.1511797112

Mekonnen, M.M., Hoekstra, A.Y., 2018. Global Anthropogenic Phosphorus Loads to Freshwater and Associated Grey Water Footprints and Water Pollution Levels: A High-Resolution Global Study. Water Resour. Res. https://doi.org/10.1002/2017WR020448

Moyle, M., Boyle, J.F., 2021. A method for reconstructing past lake water phosphorus concentrations using sediment geochemical records. J. Paleolimnol. 65, 461-478. https://doi.org/10.1007/s10933-021-00174-0

Mukundan, R., Hoang, L., Gelda, R.K., Yeo, M.-H., Owens, E.M., 2020. Climate change impact on nutrient loading in a water supply watershed. J. Hydrol. 586, 124868. https://doi.org/10.1016/j.jhydrol.2020.124868 
Nürnberg, G.K., 1984. The prediction of internal phosphorus load in lakes with anoxic hypolimnia1. Limnol. Oceanogr. 29, 111-124. https://doi.org/10.4319/lo.1984.29.1.0111

Ostrofsky, M.L., 1978. Modification of Phosphorus Retention Models for Use with Lakes with Low Areal Water Loading. J. Fish. Res. Board Canada 35, 1532-1536. https://doi.org/10.1139/f78-242

Prairie, Y.T., 1989. Statistical models for the estimation of net phosphorus sedimentation in lakes. Aquat. Sci. 51, 192-210. https://doi.org/10.1007/BF00877742

Radomski, P., Carlson, K., 2018. Prioritizing lakes for conservation in lake-rich areas. Lake Reserv. Manag. 34, 401-416. https://doi.org/10.1080/10402381.2018.1471110

Reckhow, K.H., 1988. Empirical models for trophic state in southeastern U.S. Lakes and reservoirs. J. Am. Water Resour. Assoc. 24, 723-734. https://doi.org/10.1111/j.17521688.1988.tb00923.x

Reckhow, K.H., 1979. Uncertainty analysis applied to Vollenweider's phosphorus loading criterion. J. Water Pollut. Control Fed. 51, 2123-2128.

Schindler, D.W., 2012. The dilemma of controlling cultural eutrophication of lakes. Proc. R. Soc. B Biol. Sci. 279, 4322-4333. https://doi.org/10.1098/rspb.2012.1032

Schindler, D.W., Fee, E.J., Ruszczynski, T., 1978. Phosphorous input and its consequences for phytoplankton standing crop and production in the experimental lakes area and in similar lakes. J. Fish. Res. Board Canada 35, 190-196. https://doi.org/10.1139/f78-031

Schwarz, G., 1978. Estimating the Dimension of a Model. Ann. Stat. 6. https://doi.org/10.1214/aos/1176344136

Smith, V.H., Schindler, D.W., 2009. Eutrophication science: where do we go from here? Trends Ecol. Evol. 24, 201-207. https://doi.org/10.1016/j.tree.2008.11.009

Snodgrass, W.J., O’Melia, C.R., 1975. Predictive Model for Phosphorus in Lakes. Environ. Sci. Technol. 9, 937-944. https://doi.org/10.1021/es60108a005

Søndergaard, M., Bjerring, R., Jeppesen, E., 2013. Persistent internal phosphorus loading during summer in shallow eutrophic lakes. Hydrobiologia 710, 95-107. https://doi.org/10.1007/s10750-012-1091-3

Stachelek, J., Ford, C., Kincaid, D., King, K., Miller, H., Nagelkirk, R., 2018. The National Eutrophication Survey: lake characteristics and historical nutrient concentrations. Earth Syst. Sci. Data 10, 81-86. https://doi.org/10.5194/essd-10-81-2018

Stauffer, R.E., 1985. Relationships between phosphorus loading and trophic state in calcareous lakes of southeast Wisconsin. Limnol. Oceanogr. 30, 123-145. https://doi.org/10.4319/lo.1985.30.1.0123

Tammeorg, O., Haldna, M., Nõges, P., Appleby, P., Möls, T., Niemistö, J., Tammeorg, P., Horppila, J., 2018. Factors behind the variability of phosphorus accumulation in Finnish lakes. J. Soils Sediments 18, 2117-2129. https://doi.org/10.1007/s11368-018-1973-8

Thornton, J.A., Harding, W.R., Dent, M., Hart, R.C., Lin, H., Rast, C.L., Rast, W., Ryding, S.O., 
Slawski, T.M., 2013. Eutrophication as a 'wicked' problem. Lakes Reserv. Res. Manag. 18, 298-316. https://doi.org/10.1111//re.12044

Tong, Y., Zhang, W., Wang, X., Couture, R.-M., Larssen, T., Zhao, Y., Li, J., Liang, H., Liu, X., Bu, X., He, W., Zhang, Q., Lin, Y., 2017. Decline in Chinese lake phosphorus concentration accompanied by shift in sources since 2006. Nat. Geosci. 10, 507-511. https://doi.org/10.1038/ngeo2967

USEPA, 1975. National Eutrophication Survey Methods Working Paper No. 175.

Uttormark, P.D., Hutchins, M.L., 1980. Input/Output Models as Decision Aids for Lake Restoration. J. Am. Water Resour. Assoc. 16, 494-500. https://doi.org/10.1111/j.17521688.1980.tb03903.x

Vinçon-Leite, B., Casenave, C., 2019. Modelling eutrophication in lake ecosystems: A review. Sci. Total Environ. 651, 2985-3001. https://doi.org/10.1016/j.scitotenv.2018.09.320

Vollenweider, R.A., 1976. Advances in defining critical loading levels for phosphorus in lake eutrophication., Memorie dell'Istituto Italiano di Idrobiologia, Dott. Marco de Marchi Verbania Pallanza.

Vollenweider, R.A., 1975. Input-output models - With special reference to the phosphorus loading concept in limnology. Schweizerische Zeitschrift für Hydrol. 37, 53-84. https://doi.org/10.1007/BF02505178

Vollenweider, R.A., 1969. Moglichkeiten und grenzen elementarer modelle der stoffbilanz von seen. arch. Hydrobiol 66, 1-36.

Vollenweider, R.A., 1968. The scientific basis of lake and stream eutrophication, with particular reference to phosphorus and nitrogen as eutrophication factors, Organisation for Economic Cooperation and Development, Paris.

Walker Jr, W.W., 1985. Empirical Methods for Predicting Eutrophication in Impoundments. Report 3. Phase II. Model Refinements. Concord, MA, USA.

Wu, Y., Wang, S., Ni, Z., Li, H., May, L., Pu, J., 2021. Emerging water pollution in the world's least disturbed lakes on Qinghai-Tibetan Plateau. Environ. Pollut. 272, 116032. https://doi.org/10.1016/j.envpol.2020.116032

Xu, B., Li, Y., Han, F., Zheng, Y., Ding, W., Zhang, C., Wallington, K., Zhang, Z., 2020. The transborder flux of phosphorus in the Lancang-Mekong River Basin: Magnitude, patterns and impacts from the cascade hydropower dams in China. J. Hydrol. 590, 125201. https://doi.org/10.1016/j.jhydrol.2020.125201

Xu, Z., Yu, C., Liao, L., Yang, P., Yang, Z., 2021. Optimizing reservoir operations for tradeoffs between economic objectives and legacy phosphorus management. Resour. Conserv. Recycl. 167, 105413. https://doi.org/10.1016/j.resconrec.2021.105413

Yeasted, J.G., Morel, F.M.M., 1978. Empirical Insights into Lake Response to Nutrient Loadings, with Application to Models of Phosphorus in Lakes. Environ. Sci. Technol. 12, 195-201. https://doi.org/10.1021/es60138a004 
797 Zamparas, M., Zacharias, I., 2014. Restoration of eutrophic freshwater by managing internal $798 \quad$ nutrient loads. A review. Sci. Total Environ. 496, 551-62.

799 https://doi.org/10.1016/j.scitotenv.2014.07.076

800 Zmijewski, N., Wörman, A., 2017. Trade-Offs between Phosphorous Discharge and Hydropower 801 Production Using Reservoir Regulation. J. Water Resour. Plan. Manag. 143, 04017052.

802 https://doi.org/10.1061/(ASCE)WR.1943-5452.0000809

803 